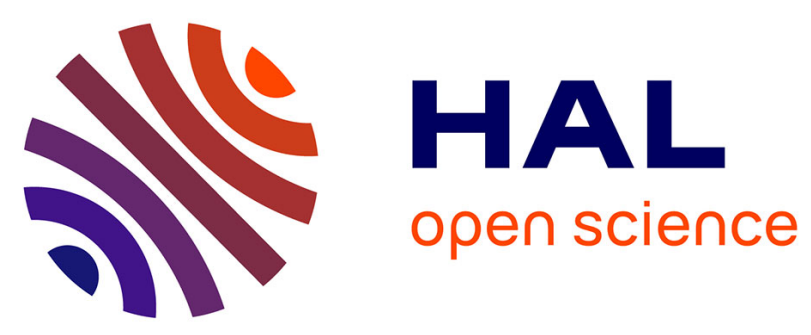

\title{
Link between Alkali Metals in Salt Templates and in Electrolytes for Improved Carbon-Based Electrochemical Capacitors
}

Anetta Platek-Mielczarek, Cristina Nita, Camelia Matei Ghimbeu, Elzbieta Frackowiak, Krzysztof Fic

\section{To cite this version:}

Anetta Platek-Mielczarek, Cristina Nita, Camelia Matei Ghimbeu, Elzbieta Frackowiak, Krzysztof Fic. Link between Alkali Metals in Salt Templates and in Electrolytes for Improved Carbon-Based Electrochemical Capacitors. ACS Applied Materials \& Interfaces, 2021, 13 (2), pp.2584-2599. 10.1021/acsami.0c18627 . hal-03319674

\section{HAL Id: hal-03319674 \\ https://hal.science/hal-03319674}

Submitted on 12 Aug 2021

HAL is a multi-disciplinary open access archive for the deposit and dissemination of scientific research documents, whether they are published or not. The documents may come from teaching and research institutions in France or abroad, or from public or private research centers.
L'archive ouverte pluridisciplinaire HAL, est destinée au dépôt et à la diffusion de documents scientifiques de niveau recherche, publiés ou non, émanant des établissements d'enseignement et de recherche français ou étrangers, des laboratoires publics ou privés. 


\title{
Link between Alkali Metals in Salt Templates and in Electrolytes for Improved Carbon-Based Electrochemical Capacitors
}

\author{
Anetta Platek-Mielczarek, Cristina Nita, Camélia Matei Ghimbeu,* Elzbieta Frackowiak, \\ and Krzysztof Fic*
}

Cite This: ACS Appl. Mater. Interfaces 2021, 13, 2584-2599

Read Online

ACCESS

山lll Metrics \& More

Article Recommendations

Supporting Information

ABSTRACT: Various alkali metal $\left(\mathrm{Li}^{+}, \mathrm{Na}^{+}, \mathrm{K}^{+}, \mathrm{Rb}^{+}\right.$, and $\left.\mathrm{Cs}^{+}\right)$chlorides with Pluronic F127 were used as a soft-salt template for tuning the textural and structural properties of carbon. Highly conductive metal hydroxide solutions, where the cations are the same as those in the salt template, have been used as electrolytes. By increasing the size of the cation in the template, the textural properties of carbon, such as the specific surface area, micropore volume, and pore size, were remarkably enhanced. It directly translates to an increase in the specific capacitance of the electrode material. For a constant current charge/ discharge at $0.1 \mathrm{~A} \mathrm{~g}^{-1}$, the electrode composed of $\mathrm{LiCl}-\mathrm{T}$ and operating with 1 mol L ${ }^{-1} \mathrm{LiOH}$ demonstrates the capacitance of $124 \mathrm{~F} \mathrm{~g}^{-1}$, whereas $\mathrm{CsCl}-\mathrm{T}$ with the same electrolyte has a capacitance of $216 \mathrm{~F} \mathrm{~g}^{-1}$. Moreover, the materials show the highest capacitance retention (up to $75 \%$ ) vs. the current regime applied when the cation used during synthesis matches the cation

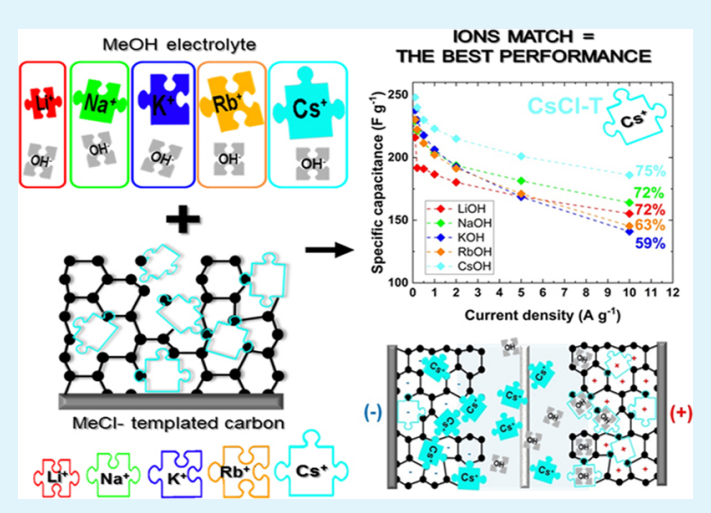
present in the electrolyte (i.e., LiCl-T with $\mathrm{LiOH}$ ). Interestingly, capacitance normalized by specific surface area has been found to be the highest when LiOH solution is applied as an electrolyte. Thus, for this metric, the size of ions seems to be a crucial parameter. The importance of mesoporosity is highlighted as well by using materials with a similar fraction of micropores and with or without mesopores. Briefly, the presence of mesopore fraction proved to be essential for improved capacity retention (69\% vs. 30\%). Besides textural properties, the graphitization degree impacts the electrochemical performance as well. It increases among the samples, in accordance with cation- $\pi$ binding energy, e.g., LiCl-T is the most "graphitic-like" material and $\mathrm{CsCl}-\mathrm{T}$ is the most disordered. Thus, the more graphitic-like materials demonstrate higher rate capability and cycle stability.

KEYWORDS: templated carbon, soft-salt template, electrochemical capacitor, aqueous electrolyte, cation match

\section{INTRODUCTION}

Currently, growing attention is being given to the sustainability and durability of energy storage systems (especially electrochemical capacitors) to accompany the energy transition. ${ }^{1}$ The energy storage market is steeped with "extraordinary", "outstanding", and "enormously high" values, which have not increased the applicability of the proposed solutions so far. ${ }^{2,3}$ Therefore, not only the high capacitance or energy values that are reported are of interest but also eco-friendly materials, facile and scalable synthesis, and testing formulations, accompanied by an in-depth understanding of ongoing processes, are also of great importance. ${ }^{3}$ Thus, new strategies for combining reasonable electrode materials with appropriate aqueous electrolytes $^{4,5}$ are sought to produce high-performance electrochemical capacitors (ECs). ${ }^{6-8}$ Regarding the electrode material properties, a substantial amount of effort has been undertaken on the design of high-surface area carbon-based electrode materials to drastically increase the energy output of the device while maintaining its high-power capability. The reported gravimetric capacitance of ECs ranges from 100 to $300 \mathrm{~F} \mathrm{~g}^{-1}$ for carbons with specific surface areas higher than $1500 \mathrm{~m}^{2}$ $\mathrm{g}^{-1} \cdot{ }^{9,10}$ Nevertheless, the preparation methods require the use of either hazardous and toxic precursors (formaldehyde and phenol), ${ }^{11}$ strong acids $\left(\mathrm{HF}, \mathrm{HCl}\right.$, and $\left.\mathrm{H}_{3} \mathrm{PO}_{4}\right),{ }^{12}$ or corrosive activation agents $(\mathrm{KOH})$, although efforts have been made recently to overcome these limitations. ${ }^{13-15}$ This is why a new strategy that combines two facile and eco-friendly carbon preparation methods, namely, soft-template ${ }^{16-19}$ and salttemplate $^{20-22}$ synthesis, has been implemented in previous studies, ${ }^{23,24}$ allowing authors to obtain a set of carbon-based materials with developed surface area and precisely tuned pores. In the literature, materials synthesized by using the soft-template approach only (i.e., without subsequent activation step)

Received: October 16, 2020

Accepted: December 15, 2020

Published: January 8, 2021 
Scheme 1. Scheme of Soft-Salt Templated Synthesis of Porous Carbons

\section{ONE-POT soft-salt templated synthesis}

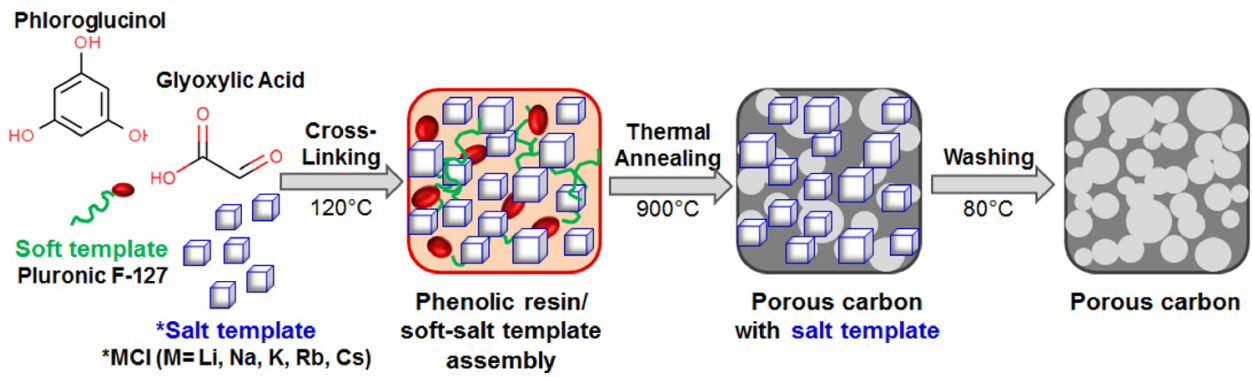

demonstrate a moderate specific surface area that rarely exceeds $1000 \mathrm{~m}^{2} \mathrm{~g}^{-1} \cdot{ }^{16-19}$ Soft templates exploiting surfactant molecules provide mesopores; these mesopores are assumed to originate from the formation of the micelles by surfactant self-assembly. Therefore, such a large molecule agglomeration cannot contribute to the development of high surface area. Contrary, materials obtained by the salt-template approach could surpass the specific surface area values of $1200 \mathrm{~m}^{2} \mathrm{~g}^{-120-22}$ as the salt actively participates in a carbon activation process and contributes to the micropore formation. The synergy of the soft and salt templates results in materials with improved textural features (well-balanced micro- and mesopore volume, high surface area, and tunable pore size/geometry). Given that, carbon materials with a high specific surface area, ranging from 1150 to $2556 \mathrm{~m}^{2} \mathrm{~g}^{-1}$, have been obtained by using $\mathrm{LiCl}$ and $\mathrm{CsCl}$ templates, respectively. ${ }^{23,24}$ Besides the eco-friendly nature of the involved precursors and solvents, this approach allows for a single-step templating and activation process (during the annealing), contrary to other methods with carbonization and activation steps being usually independent and resulting in twoor even three-step synthesis methods.

To date, the comprehensive study of carbon material features and their electrochemical properties is triggering the attention of scientists. ${ }^{25}$ A high specific surface area does not simply lead to an improved electrochemical performance, such as an increased specific capacitance or long-term performance. It has been stated that micropores are mainly relevant for the formation of a developed electric double layer (EDL), while mesopores are considered channels for electrolyte ion fluxes. ${ }^{26,27}$ It is also claimed that the appropriate distribution of meso- and micropores plays a major role in the ion transport process. ${ }^{28}$ Systematic studies provided insight into the carbon propertycarbon electrochemical behavior relationship. Furthermore, it has been explained that an adequate pore size improves the electrochemical behavior of carbon-based electrodes more than a high surface area. ${ }^{29}$ For example, a linear dependence of the specific capacitance vs. specific surface area (SSA) has been found in $6 \mathrm{~mol} \mathrm{~L}^{-1} \mathrm{KOH}$ for certain SSA ranges. In particular, interesting observations have been made in terms of the presence of ultramicropores, which dramatically increases the gravimetric capacitance. Another study improved the understanding of pore volume filling during EDL formation. ${ }^{30}$ Using solvent-free ionic liquids as the electrolyte, it was possible to calculate the accessible pore volume as a function of the obtained specific capacitance. It was demonstrated that a set of carbon materials used a maximum of $60 \%$ of their overall (available) pore volume. Moreover, it was shown that decreasing the size of cations present in the electrolyte resulted in an increase in the specific capacitance of a symmetric EC. An important difference in the power response of microporous or mesoporous carbons was demonstrated in a $30 \mathrm{wt} \% \mathrm{KOH}$ solution. ${ }^{31}$ Finally, one must keep in mind that an estimation of the specific surface area based on adsorption techniques might come with some limitations, and particular attention should be paid to the data interpretation and correlation. ${ }^{9,32-34}$

It was also confirmed that not only the pore size but also the structure of the pore network plays an important role in the power output and high-frequency performance. However, one needs to bear in mind that microporous carbons allow a high energy output to be obtained, while the mesoporous structure is responsible for producing a high power. The best ratio of retained capacitance (90\%) was found for a 2D hexagonal mesopore network structure, while microporous carbon was characterized by very poor rate handling (20\%). All abovementioned conclusions and observations were summarized in subsequent reports. ${ }^{35-37}$ It has been already reported and proven that, even though the pore diameter in the nano-range exceeds dimension of ions present in the electrolyte solution, it can be still beneficial as normalized specific capacitance increases when nanostructured electrodes are used in ECs. This phenomenon is related with close matching of a bare ion size with the pore size. However, one needs to bare in mind that overestimation of specific surface area, especially in the nanopore size range, might be a crucial factor in the explanation of this behavior. To date, in the literature, there is still an attempt to find a universal carbon textural and structural propertycarbon electrochemical performance dependency., ${ }^{9,38-41}$ Some works emphasize carbon features; however, these reports do not explain in detail the origin of specific electrochemical behaviors. $^{42-45}$ This proves that an understanding of the relationship between the structural or textural features of carbon materials and their electrochemical response is very complex.

Considering the previous works, we report herein on the great potential of carbon materials obtained by a facile and sustainable soft-salt template method that were applied as electrodes for electrochemical capacitor applications. A systematic study of five salt templated carbons (with $\mathrm{LiCl}, \mathrm{NaCl}, \mathrm{KCl}, \mathrm{RbCl}$, and $\mathrm{CsCl}$ as the templates) with their respective hydroxide solutions (as the electrolytes) that contained the same cation as those used for carbon synthesis ( $\mathrm{LiOH}, \mathrm{NaOH}, \mathrm{KOH}, \mathrm{RbOH}$, and $\mathrm{CsOH}$ ) was conducted to find and explain the influence of the carbon texture/structure on the electrochemical performance. Thus, we report on the correlations between (i) textural properties and the type of cation from the salt template; (ii) the specific surface area and the specific capacitance; (iii) the cation size present in the electrolyte and the capacitance value; and (iv) the carbon material pore size/electrolyte ion size matching. Novel correlations, such as the relationship between the cation/carbon 
pore size matching and the capacitance retention or graphitization degree of the material and the binding energy of the cation used during synthesis, were observed and provided insight into the complexity of carbon material/electrolytic solution interactions.

\section{MATERIALS AND CHARACTERIZATION}

2.1. Materials Preparation. 2.1.1. Preparation of the Carbon Materials. The synthesis protocol of the carbon materials is illustrated in Scheme 1 and described in detail elsewhere. ${ }^{23,24}$ The soft-salt template approach first involves the dissolution of a carbon source, i.e., phloroglucinol (1,3,5-benzenetriol, $\left.\mathrm{C}_{6} \mathrm{H}_{6} \mathrm{O}_{3}\right)(0.83 \mathrm{~g})$, and a crosslinker, i.e., glyoxylic acid monohydrate $\left(\mathrm{C}_{2} \mathrm{H}_{2} \mathrm{O}_{3} \cdot \mathrm{H}_{2} \mathrm{O}\right)(0.78 \mathrm{~g})$ in the ethanol and water mixture $(10 / 20 \mathrm{~mL})$, to form an eco-friendly phenolic resin. The triblock copolymer Pluronic F127 [poly(ethylene oxide)-block-poly(propylene oxide)-block-poly(ethylene oxide, $\left.\left.\mathrm{PEO}_{106} \mathrm{PPO}_{70} \mathrm{PEO}_{106}, M_{\mathrm{w}}=12,600 \mathrm{Da}\right)\right]$ as a soft template was added $(1.6 \mathrm{~g})$ to the same solution. It enables the formation of micelles, which are further assembled with the phenolic resin via hydrogen and/ or covalent bondings to form a macromolecular assembly. Sodium hydroxide $\left(\mathrm{NaOH}, 1.25 \mathrm{~mol} \mathrm{~L}^{-1}\right)$ was used so that the $\mathrm{pH}$ during the synthesis of the materials was 5; $\mathrm{NaOH}$ was used according to the $\mathrm{pH}$ influence on the specific surface area development established elsewhere. ${ }^{23}$ Subsequently, a salt template comprising lithium chloride $(\mathrm{LiCl})$, sodium chloride $(\mathrm{NaCl})$, potassium chloride $(\mathrm{KCl})$, rubidium chloride $(\mathrm{RbCl})$, or cesium chloride $(\mathrm{CsCl})$ was added to the reaction volume. The molar ratio of 2:1 was kept between the salt and the phenolic resin. The obtained solution was dispatched in several Petri dishes to evaporate at room temperature, held at $120^{\circ} \mathrm{C}$ for $6 \mathrm{~h}$ to crosslink the phenolic resin, and then annealed at $900{ }^{\circ} \mathrm{C}$ for $1 \mathrm{~h}$ in Ar flow. During the annealing step, the thermal decomposition of phenolic resin induces the formation of the carbon framework with a certain degree of micropores, whereas the mesopores are formed as a result of softtemplate decomposition. The final product was washed thoroughly using hot, distilled water $\left(80{ }^{\circ} \mathrm{C}\right)$ to remove residues of chloride salt (thus, can be used again). The recovery rate of salts has been found to be $>80 \%$, i.e., $86 \%$ when $\mathrm{CsCl}$ has been used. During this step, additional micropores are created in the carbon material due to the salttemplate removal. Additionally, one sample without a soft template was prepared to verify its significance in the synthesis protocol. All the chemical products were purchased from Sigma-Aldrich. For clarity, samples were labeled with the salt template used for the preparation $(\mathrm{MeCl})$ and an indication of the presence $(\mathrm{T})$ or absence $(\mathrm{NT})$ of Pluronic F127 soft template as follows: LiCl-T, NaCl-T, KCl-T, RbCl$\mathrm{T}$, CsCl-T, and KCl-NT.

2.1.2. Preparation of the Electrode Materials. The electrode material in the form of a self-standing film was prepared by grinding and mixing 90 wt \% soft-salt templated carbon, 5 wt \% polymer binder (PTFE $60 \mathrm{wt} \%$ in $\mathrm{H}_{2} \mathrm{O}$, Sigma-Aldrich), and $5 \mathrm{wt} \%$ carbon soot (C65, Timcal Company). Ethanol was used as a dispersive agent. Next, the evaporation temperature was established at $70^{\circ} \mathrm{C}$. Such an electrode composition allows the electrode material to be formed without coating on the current collector. Instead, the electrode material is rolled in a freestanding film, dried at $100{ }^{\circ} \mathrm{C}$ in a vacuum, and cut into round discs with a diameter of $10 \mathrm{~mm}$. The average electrode mass was $9 \mathrm{mg}$.

2.2. Materials Characterization. 2.2.1. Physicochemical Characterization. X-ray powder diffraction (XRD) was implemented to characterize the carbon structure using a D8 ADVANCE A25 diffractometer from Bruker in the $\theta-\theta$ Bragg-Brentano reflection geometry. This instrument was equipped with a Lynx Eye XE-T highresolution energy dispersive 1-D detector $\left(\mathrm{Cu} \mathrm{K} \alpha_{1,2}\right)$ that allowed ultrafast X-ray diffraction measurements. The material surface morphology was investigated by transmission electron microscopy (TEM) on a JEOL ARM-200F that was operated at $200 \mathrm{kV}$. The Raman analyses for powders and electrode materials were performed at room temperature in a backscattering geometry using a LabRAM BX40 (Horiba Jobin Yvon) microspectrometer equipped with a $\mathrm{He}-\mathrm{Ne}$ excitation source (wavelength of $532 \mathrm{~nm}$ ). ${ }^{46}$ The textural properties of the carbon powders and carbon-based electrodes were evaluated using $\mathrm{N}_{2}$ and $\mathrm{CO}_{2}$ adsorption isotherms. The $\mathrm{N}_{2}$ adsorption/desorption isotherms for powders were measured with a Micromeritics ASAP 2020 device at 77 $\mathrm{K}$. The powder samples were outgassed in vacuum at $300^{\circ} \mathrm{C}$ for $12 \mathrm{~h}$ before the adsorption analysis. The electrode materials were tested with a Micromeritics ASAP 2460 at $77 \mathrm{~K}$ and degassed at $100{ }^{\circ} \mathrm{C}$ with flowing helium for $24 \mathrm{~h}$ and degassed again for $5 \mathrm{~h}$ in a vacuum. The specific surface area $\left(S_{\mathrm{BET}}\right)$ was calculated by the Brunauer-EmmettTeller (BET) model from the linear dependence at relative pressures ranging from 0.01 to 0.05 . Moreover, the cumulative surface area $\left(S_{\text {CUM }}\right)$ from the 2D-NLDFT model was noted for all samples. The micropore volume $\left(V_{\text {micro }}\right)$ was obtained using the DubininRadushkevich equation in the relative pressure interval $\left(p / p_{0}\right)$ from $10^{-4}$ to $10^{-2}$. The pore size distribution (PSD) was determined from the adsorption branch of nitrogen isotherms using the 2D-NLDFT heterogeneous surface model for carbon materials implemented in SAIEUS (Micromeritics). The same Micromeritics ASAP 2020 device was used for the $\mathrm{CO}_{2}$ measurements, but at $273 \mathrm{~K}$, the outgassing conditions were the same as previously indicated for the powder and electrode materials. The specific surface area for $\mathrm{CO}_{2}$ measurement was calculated according to the Brunauer-Emmett-Teller $\left(S_{\mathrm{BET}}\right)$ equation.

The determination of micropore average diameter $\left(L_{0}\right)$ was performed in accordance with the formula

$$
L_{0}=\frac{1}{n} \sum_{i=1}^{n} \frac{w \cdot \frac{\mathrm{d} V}{\mathrm{~d} w}}{\frac{\mathrm{d} V}{\mathrm{~d} w}} \quad\left[\frac{\mathrm{nm} \cdot \frac{\mathrm{cm}^{3}}{\mathrm{~nm}}}{\frac{\mathrm{cm}^{3}}{\mathrm{~nm}}}=\mathrm{nm}\right]
$$

where $L_{0}$ is the average pore diameter $[\mathrm{nm}], w$ is the pore width $[\mathrm{nm}]$, and $\frac{\mathrm{d} V}{\mathrm{~d} w}$ is the differential pore volume per pore width $\left[\mathrm{cm}^{3} \mathrm{~nm}^{-1}\right]$.

2.2.2. Electrolytes Used. Highly conductive electrolytes were used to study the electrode material performance in detail. Lithium, sodium, potassium, rubidium, and cesium hydroxides (Sigma-Aldrich, 99\% purity) were prepared as $1 \mathrm{~mol} \mathrm{~L}^{-1}$ solutions with distilled water. Their physicochemical characteristics are presented in Table S1 (Supporting Information).

2.2.3. Electrochemical Characterization. All electrochemical investigations were conducted in a symmetric Swagelok system using a VMP3 multichannel potentiostat/galvanostat from BioLogic (France). Glass Fiber filter paper $(12 \mathrm{~mm}$ round discs of $260 \mu \mathrm{m}$ thickness) was used as a separator. The main goal was to perform a fundamental study on the series of micro/mesoporous materials within the field of high-rate electrochemical storage devices. A set of cyclic voltammetry $\left(1-100 \mathrm{mV} \mathrm{s}^{-1}\right)$, galvanostatic charge/discharge $(0.1-10$ $\mathrm{A} \mathrm{g}^{-1}$ ), and impedance spectroscopy measurements at 0 and $0.8 \mathrm{~V}$ (in the frequency range of $100 \mathrm{kHz}$ to $1 \mathrm{mHz}$ ) were conducted. The specific capacitance was calculated per mass of electrode according to formula 2:

$$
C=\frac{2 \cdot I \cdot t}{U \cdot m_{\text {ele }}}=\frac{4 \cdot A_{\text {integral }} I}{U^{2} \cdot m_{\text {ele }}} \quad\left[\frac{\mathrm{A} \cdot \mathrm{s}}{\mathrm{V} \cdot \mathrm{g}}=\frac{\mathrm{V} \cdot \mathrm{s} \cdot \mathrm{A}}{\mathrm{V}^{2} \cdot \mathrm{g}}=\frac{\mathrm{F}}{\mathrm{g}}\right]
$$

where $C$ is the gravimetric capacitance $\left[\mathrm{F} \mathrm{g}^{-1}\right], I$ is the current $[\mathrm{A}], t$ is the time of discharge $[\mathrm{s}], U$ is the voltage applied $[\mathrm{V}], A_{\text {integral }}$ is the integration of constant current discharge curve $[\mathrm{V} \mathrm{s}]$, and $m_{\mathrm{ele}}$ is the mass of one electrode $[\mathrm{g}]$. A regular slope was observed on the constant current discharge curves. Thus, it was shown that only electrostatic charge accumulation was present in the systems.

\section{RESULTS AND DISCUSSION}

3.1. Physicochemical Characterization. The soft-salt template carbon powder materials were evaluated from the physicochemical point of view to understand the correlation between their structure and texture with the electrochemical performance.

To properly explain and understand the properties of carbon materials, one needs to consider the properties of the cations used during the synthesis procedure. In Table 1, the cation size, 
Table 1. Parameters Related to Cations Used in the Salt Template and Electrolytic Solution ${ }^{a}$

\begin{tabular}{|c|c|c|c|c|c|c|}
\hline cation & $\begin{array}{l}\text { crystal ionic diameter } \\
{[\mathrm{nm}]^{47}}\end{array}$ & $\begin{array}{l}\text { solvated cation } \\
\text { diameter }^{b}[\mathrm{~nm}]^{48}\end{array}$ & $\begin{array}{l}\text { hydration enthalpy } \\
\qquad\left[\mathrm{kJ} \mathrm{mol}{ }^{-1}\right]^{23}\end{array}$ & $\begin{array}{l}\text { binding energy } \\
{\left[\mathrm{kcal} \mathrm{mol}^{-1}\right]^{23}}\end{array}$ & $\begin{array}{l}\text { melting point of chloride } \\
\text { salts }\left[{ }^{\circ} \mathrm{C}\right]\end{array}$ & $\begin{array}{l}\text { crystal structure of } \\
\text { chloride salts }\end{array}$ \\
\hline $\mathrm{Li}^{+}$ & 0.152 & 0.420 & 520 & 38 & 615 & FCC \\
\hline $\mathrm{Na}^{+}$ & 0.232 & 0.486 & 406 & 28 & 801 & FCC \\
\hline $\mathrm{K}^{+}$ & 0.304 & 0.568 & 322 & 19 & 770 & FCC \\
\hline $\mathrm{Rb}^{+}$ & 0.332 & 0.594 & 297 & 16 & 718 & FCC \\
\hline $\mathrm{Cs}^{+}$ & 0.362 & 0.650 & 276 & $<$ & 645 & BCC \\
\hline
\end{tabular}
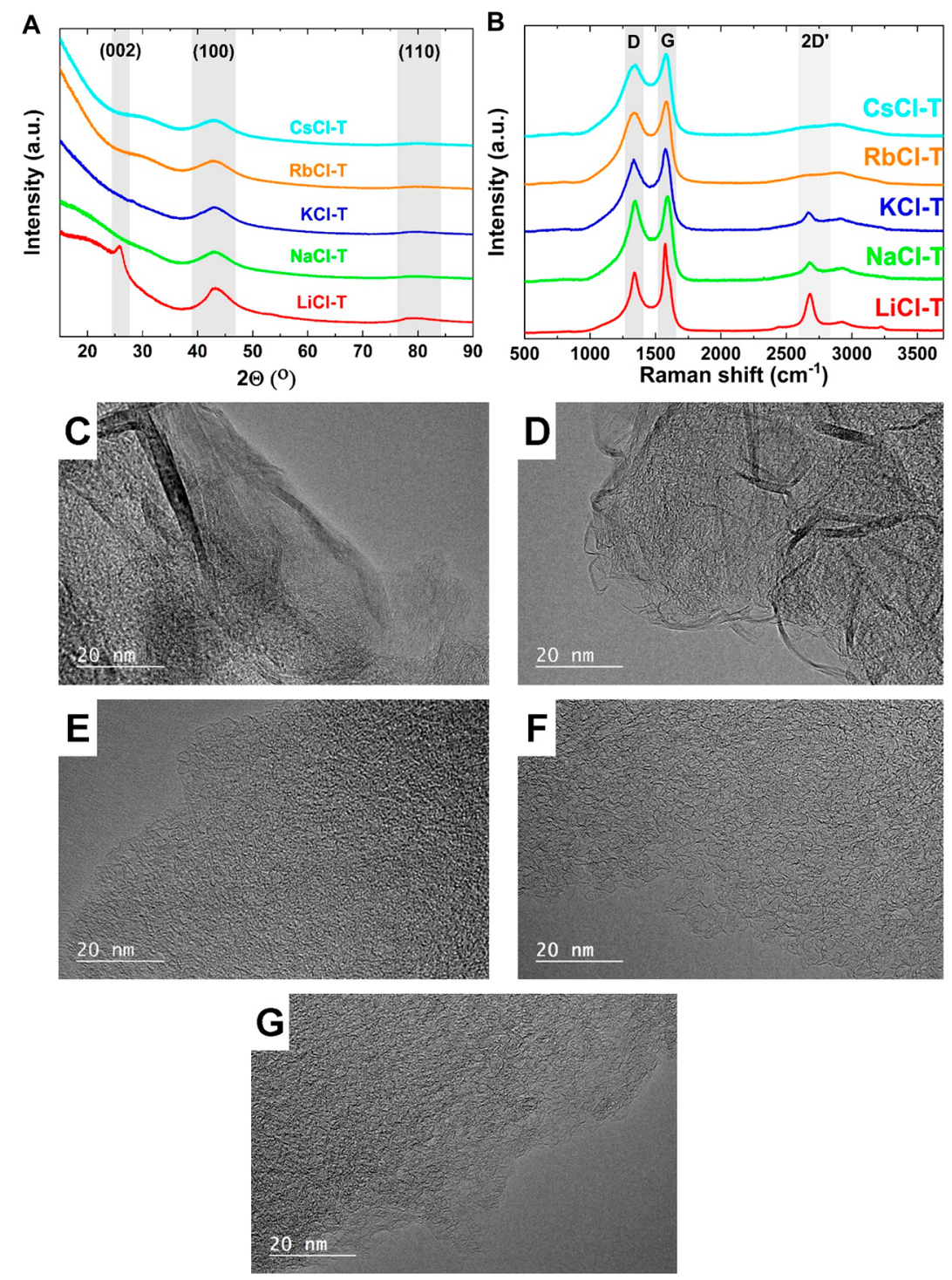

Figure 1. Structural characterization of the materials: XRD patterns (a), Raman spectra (b), and TEM images for carbon powders synthesized with different salt templates: LiCl-T (c), NaCl-T (d), KCl-T (e), RbCl-T (f), and CsCl-T (g).

cation $-\pi$ binding energy, hydration enthalpy, and melting point of chloride salts are shown.

The carbon materials herein were prepared by a combined soft-salt template approach that conveniently produced carbon materials with an improved microporosity and specific surface area. In this process, several events occur depending on the synthesis stage (solution preparation, drying, and thermal annealing) but also on the metal in the salt used. There may be different interactions with the solvent, the phenolic resin molecules and the carbon network. For this particular solution composition, relations between precursors were widely described elsewhere. ${ }^{23}$ First of all, Pluronic F127 soft-template forms micelles necessary for mesopore formation. It is predicted that they form a hydrophobic core-hydrophilic corona shape. However, the features of the micelles strongly depend on the type of salt used as a salt template. In addition, the polymerization between phloroglucinol and glyoxylic acid occurs to form the phenolic resin, which develop a specific interaction with the hydrophilic corona of the pluronic template, resulting in a macromolecular assembly. On the other hand, the 
presence of inorganic salts accelerates the polymerization reactions and modifies the size/shape of micelles. Thus, interactions of various nature compete with each other between all solution components. Moreover, the anions are known to impact much stronger the micelle and polymerization reactions. As $\mathrm{NaOH}$ is used for $\mathrm{pH}$ adjustment, the $\mathrm{OH}^{-}$presence induces dehydration of pluronic and disorganization of the micelles, thus controlling the pore formation. Therefore, to simplify the studied case, all syntheses were performed at $\mathrm{pH} 5$.

For discussing salt template features, its crystal ionic diameter, solvation cation diameter, hydration enthalpy, cation $-\pi$ binding energy, melting point, and crystal structure have to be considered (Table 1). At the solution stage, a strong competition by the salt cations for the water molecules and aromatic rings in the phloroglucinol-based phenolic resin takes place. The hydration enthalpy and cation- $\pi$ binding energy impact such interactions. Later, during the annealing step, the cation- $\pi$ binding energy of the cations to the aromatic carbon rings and the melting point of the salt used may both affect the porosity and the structure of the carbon material. ${ }^{23}$ All the modifications that were triggered by a systematic series of five metal salts are discussed in detail below.

3.1.1. Materials Structure. The structural properties of the synthesized carbon materials were determined by several complementary techniques: XRD, Raman spectroscopy, and TEM.

The XRD patterns (Figure 1a) of LiCl-T present diffraction peaks at 2 theta values of $26^{\circ}, 43^{\circ}$, and $78^{\circ}$, corresponding to the (002), (100), and (110) diffraction planes of hexagonal graphite (PDF-411487), respectively. For the other materials, the (002) peak that is associated with the stacking of graphene planes has a very low intensity and is broad, indicating disordered carbon materials, which is in good agreement with the data from other porous carbon materials. ${ }^{49}$ Moreover, it can be seen for all materials that the (100) peak related to the graphene lateral size (length) is more intense than the (002) peak, and its intensity changes as follows: $\mathrm{LiCl}-\mathrm{T}>\mathrm{NaCl}-\mathrm{T}>\mathrm{KCl}-\mathrm{T}>\mathrm{RbCl}-\mathrm{T}>\mathrm{CsCl}-$ $\mathrm{T}$. Evidence of graphene sheet stacking, which is called the "falling card model", has been introduced to explain the internal structure of hard carbons. ${ }^{49}$ However, this model seems to be adequately correlated with favorable micropore coalescence in the presence of cations having a high binding energy (such as $\mathrm{Li}^{+}$) to carbon aromatic rings, which forces graphene sheets to form stacks. Additionally, the local structural properties of carbons were investigated by Raman spectroscopy (Figure 1b, Figure S1, and Table S2). The Raman spectra for all materials present the disorder-induced peak (D) and first-order graphite peak (G) specific for carbon materials at 1350 and $1580 \mathrm{~cm}^{-1}$, respectively. An overtone of the $\mathrm{D}$ peak (also denoted as $2 \mathrm{D}$ ) could be observed at $2700 \mathrm{~cm}^{-1}$, especially for the $\mathrm{Li}-, \mathrm{Na}-$, and $\mathrm{K}$-based materials. This is worth noting that the intensity of this peak varies from one zone to another, as emphasized by the Raman mapping provided in Figure $\mathrm{Sla}-\mathrm{c}$ (Supporting Information). This observation is in line with the TEM images showing a mixture of highly disordered and graphitic-like zones. Differently, for $\mathrm{RbCl}-\mathrm{T}$ and $\mathrm{CsCl}-\mathrm{T}$, the $2 \mathrm{D}$ peak is very broad and rather similar through the material (Figure S1d, Supporting Information), confirming their homogeneous structure, in fair agreement with TEM. This result reflects the interactions between stacked graphitic $\left(\mathrm{sp}^{2}\right)$ layers. One might say that the intensity of this peak follows the order LiCl- $\mathrm{T}>\mathrm{NaCl}-\mathrm{T}>\mathrm{KCl}$ $\mathrm{T}>\mathrm{RbCl}-\mathrm{T}>\mathrm{CsCl}-\mathrm{T}$, which is in accordance with the presence of the (002) and (100) peaks in the XRD patterns. Moreover, the Raman spectrum for LiCl-T only demonstrates a $\mathrm{D}^{\prime}$ overtone in the $\mathrm{G}$ peak that represents graphitic domains. The $I_{\mathrm{D}} / I_{\mathrm{G}}$ ratio was calculated as an average of 11 different measurements over the powder sample surface. All synthesized materials had $I_{\mathrm{D}} / I_{\mathrm{G}}$ ratios lower than 1 considering the intensity of the peaks (the $I_{\mathrm{D}} / I_{\mathrm{G}}$ was 0.70 for LiCl-T, 0.91 for NaCl-T, 0.84 for $\mathrm{KCl}-\mathrm{T}, 0.88$ for $\mathrm{RbCl}-\mathrm{T}$, and 0.88 for $\mathrm{CsCl}-\mathrm{T}$ ), indicating that the intensity of the $\mathrm{G}$ peak was always slightly higher than that of the $\mathrm{D}$ peak. A comparison of the $I_{\mathrm{D}} / I_{\mathrm{G}}$ values for the pristine carbon and electrode materials are provided in Table S2 (Supporting Information). Only negligible changes were observed after composing the electrode (with 5 wt \% conductive carbon additive and 5 wt $\%$ polymer binder). When the $I_{\mathrm{D}} / I_{\mathrm{G}}$ ratio was calculated based on the deconvolution of the Raman spectra (by applying the Lorentzian model) and their area ratio, the values were 1.32 for $\mathrm{LiCl}-\mathrm{T}, 2.19$ for $\mathrm{NaCl}-\mathrm{T}, 2.03$ for $\mathrm{KCl}-\mathrm{T}, 2.45$ for $\mathrm{RbCl}-\mathrm{T}$, and 2.48 for $\mathrm{CsCl}-\mathrm{T}$. This proves that, among the samples, LiCl-T had the most organized structure, $\mathrm{NaCl}-\mathrm{T}$ and $\mathrm{KCl}-\mathrm{T}$ had more disordered structures with the preservation of some graphitic domains, and $\mathrm{RbCl}-\mathrm{T}$ with $\mathrm{CsCl}-\mathrm{T}$ did not contain any stacked graphene-like sheets in their structures. Moreover, the sharp $\mathrm{G}$ peak with visible $\mathrm{D}^{\prime}$ and $\mathrm{G}^{\prime}$ peaks confirmed the predominance of graphitic domains in the LiCl-T sample. The TEM images of the carbon samples are presented in Figure 1c-g. The LiCl-T (Figure 1c) sample reveals long graphitic domains (stacked graphene-like sheets) that overlapped and slightly folded. The NaCl-T (Figure 1d) image demonstrates the presence of short and thin graphitic domains but represents a mostly porous structure. This affected the (002) and (100) peaks in the XRD spectra. Samples KCl-T (Figure 1e), RbCl-T (Figure 1f), and CsCl-T (Figure 1g) were very comparable, consisting of disordered domains. Moreover, those samples were characterized by a more homogeneous structure.

The applied synthesis protocol was exactly the same among all samples (e.g., molar ratio of the precursors, temperature, and time). A single factor differentiating these carbons was the cation type in the salt template. The annealing temperature was maintained at $900^{\circ} \mathrm{C}$, which caused all salts to melt, according to Table 1 . However, the melting temperature did not depend on the cation type $(\mathrm{LiCl} \approx \mathrm{CsCl}<\mathrm{NaCl}>\mathrm{KCl}>\mathrm{RbCl})$; thus, the contributions of $\mathrm{LiCl}$ and $\mathrm{CsCl}$ might be assumed to be similar as their melting temperatures are equal to 615 and $645{ }^{\circ} \mathrm{C}$, respectively. Nonetheless, LiCl-T and CsCl-T differed greatly. The lithium-based carbon had the most graphitic structure, and the cesium-based carbon had a disordered structure similar to that of $\mathrm{RbCl}$ and $\mathrm{KCl}$. Thus, this factor was excluded as a reliable explanation for the different carbon structures among the synthesized samples. What can also be considered is the binding energy between the cations and aromatic rings (cation- $\pi$ junction). It decreased with increasing atomic mass, i.e., $\mathrm{Li}^{+}>$ $\mathrm{Na}^{+}>\mathrm{K}^{+}>\mathrm{Rb}^{+}>\mathrm{Cs}^{+}$(Table 1$)$; thus, the smallest cations $\left(\mathrm{Li}^{+}\right.$, $\mathrm{Na}^{+}$) possessing high binding energy induced better carbon graphitization, explaining the intensity of the (002) and (110) peaks in the XRD spectra and the $2 \mathrm{D}$ peak in the Raman spectra, which are more accentuated in these cases. In summarizing the results from the XRD, Raman, and TEM studies, one might say that the graphitization degree of those materials was in accordance with the order proposed above. Therefore, the binding energy of the cations to the carbon aromatic rings during the synthesis process was the main factor that impacted the final structure. 
Table 2. Textural Properties of the Synthesized Materials in a Powder State by $\mathrm{N}_{2}$ and $\mathrm{CO}_{2}$ Adsorption

\begin{tabular}{|c|c|c|c|c|c|c|c|}
\hline \multirow[b]{2}{*}{ material } & \multicolumn{5}{|c|}{$\mathrm{N}_{2}$ adsorption } & \multicolumn{2}{|c|}{$\mathrm{CO}_{2}$ adsorption } \\
\hline & $S_{\mathrm{BET}}\left(\mathrm{m}^{2} \mathrm{~g}^{-1}\right)$ & $S_{\text {CUM }}\left(\mathrm{m}^{2} \mathrm{~g}^{-1}\right)$ & $V_{\text {MICRO }}\left(\mathrm{cm}^{3} \mathrm{~g}^{-1}\right)$ & $L_{0 \text { MICRO }}(\mathrm{nm})$ & $V_{\text {MESO }}\left(\mathrm{cm}^{3} \mathrm{~g}^{-1}\right)$ & $S_{\mathrm{BET}}\left(\mathrm{m}^{2} \mathrm{~g}^{-1}\right)$ & $V_{\text {MICRO }}\left(\mathrm{cm}^{3} \mathrm{~g}^{-1}\right)$ \\
\hline $\mathrm{LiCl}-\mathrm{T}$ & 1150 & 1202 & 0.40 & 0.73 & 0.37 & 753 & 0.29 \\
\hline $\mathrm{NaCl}-\mathrm{T}$ & 1353 & 1501 & 0.44 & 0.79 & 0.37 & 843 & 0.40 \\
\hline $\mathrm{KCl}-\mathrm{T}$ & 1673 & 1858 & 0.61 & 0.68 & 0.23 & 1143 & 0.53 \\
\hline $\mathrm{RbCl}-\mathrm{T}$ & 2077 & 2058 & 0.77 & 0.77 & 0.19 & 1344 & 0.57 \\
\hline $\mathrm{CsCl}-\mathrm{T}$ & 2556 & 2245 & 0.95 & 0.88 & 0.20 & 1373 & 0.53 \\
\hline
\end{tabular}

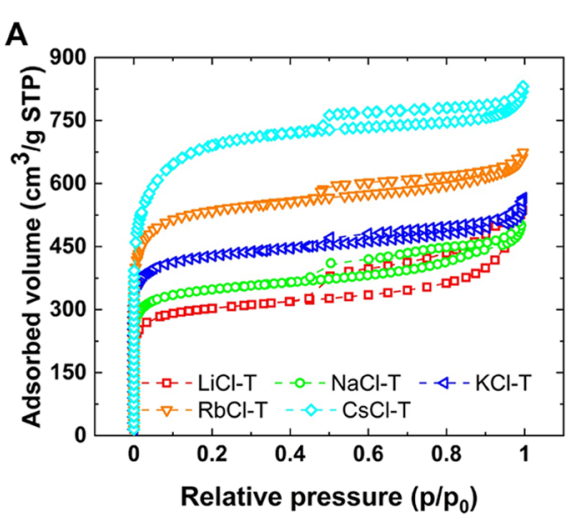

C

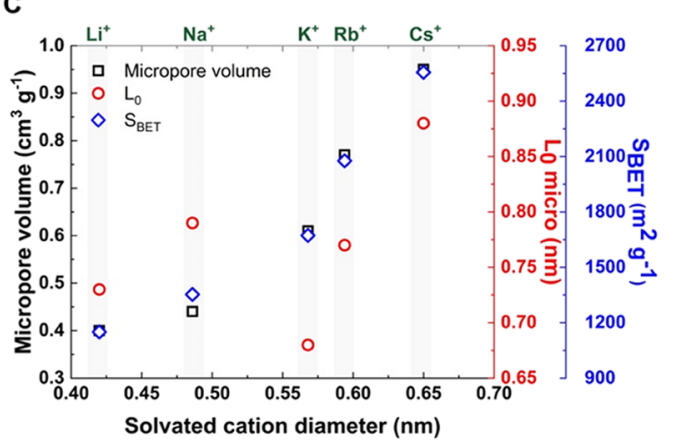

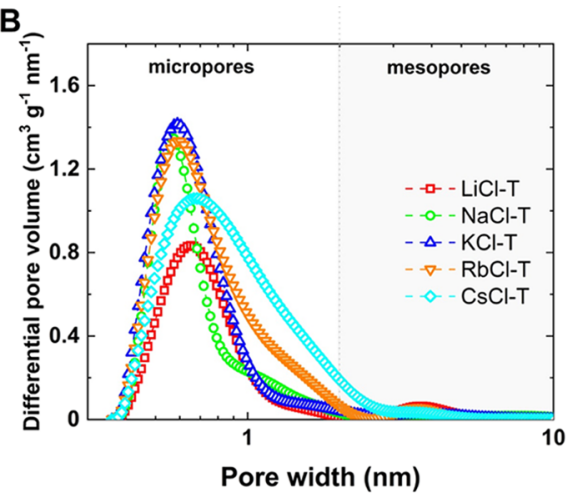

D

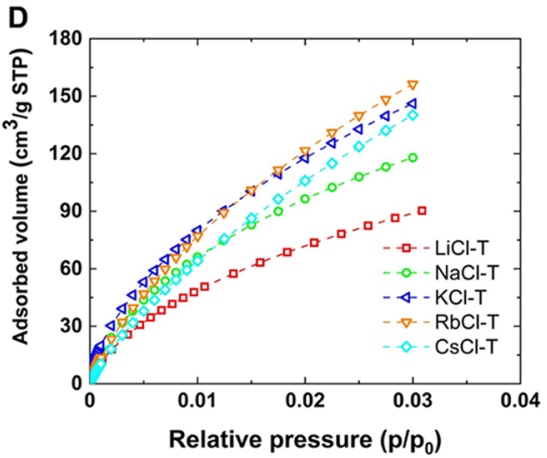

Figure 2. Textural characterization of materials: adsorption/desorption isotherms for $\mathrm{N}_{2}$ adsorption at $77 \mathrm{~K}$ (a); pore size distribution calculated from the 2D-NLDFT model for $\mathrm{N}_{2}$ adsorption (b); correlation of porosity parameters with cation diameter in the salt template used during synthesis (c); and adsorption isotherms for $\mathrm{CO}_{2}$ at $273 \mathrm{~K}$ (d).

3.1.2. Materials Texture. For an accurate understanding of the correlation between the physicochemical properties of the materials and their electrochemical performance, the textural properties of the pristine carbonaceous materials and their corresponding electrodes (90 wt \% carbon) were also investigated. Importantly, in most previous works, the electrode properties are often not discussed, and the characterization is limited to carbon. In addition, carbon materials were evaluated both by $\mathrm{N}_{2}$ and $\mathrm{CO}_{2}$ adsorption. Herein, we focus on the pristine carbon material texture. Thus, Table 2 and Figure $2 a-d$ contain information about the synthesized materials, while Table S3 presents the adsorption results for the corresponding electrode materials. The formation of a self-standing electrode did not destroy the carbonaceous material features, which can be seen from a comparison of the powder state and electrode adsorption results. The presence of a polymer binder only filled a portion of the pores, as indicted by a decreased $S_{\mathrm{BET}}, S_{\mathrm{CUM}}$, and $V_{\mathrm{MICRO}}$. However, for all synthesized materials, those parameters were changed to the same extent due to the same amount of PTFE and carbon additive used during electrode preparation (10 wt $\%)$.
All presented isotherms (Figure 2a) could be characterized as types I and IV according to the IUPAC classification. The increase adsorbed amount of gas in the low relative pressure region indicated the presence of microporosity ( $V_{\text {MICRO }}$ between $0.40 \mathrm{~cm}^{3} \mathrm{~g}^{-1}$ for LiCl-T and $0.95 \mathrm{~cm}^{3} \mathrm{~g}^{-1}$ for CsCl$\mathrm{T})$ related to the type I isotherm. The presence of the hysteresis loop corroborated the developed mesoporosity $\left(V_{\mathrm{MESO}}\right.$ between $0.37 \mathrm{~cm}^{3} \mathrm{~g}^{-1}$ for LiCl-T and $0.20 \mathrm{~cm}^{3} \mathrm{~g}^{-1}$ for CsCl-T, which represents $48 \%$ and $17 \%$ of the total pore volume, respectively) that is associated to the type IV isotherm. As the micropore fraction increased, the mesopore fraction decreased with increasing atomic mass/cation size of the alkali metal in the template. This proves that the cation type also influenced the mesoporosity. When the binding energy between the cations and carbon aromatic rings was high, the fraction of mesoporosity was higher than in the case of a low binding energy. Thus, increasing the cation size increased the micropore volume, and the same trend was observed for the specific surface area.

Intriguingly, the same correlation was not observed for the average micropore diameter as for the micropore volume $\left(V_{\text {micro }}\right)$ trend according to the cation size (Table 2 and Figure $2 b, c)$, which indicated the presence of no unequivocal order. We 
A

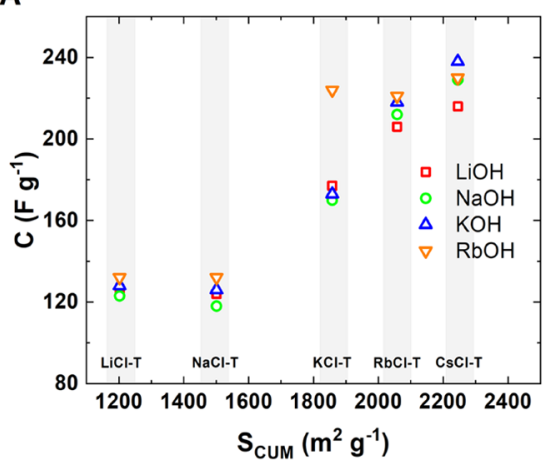

C

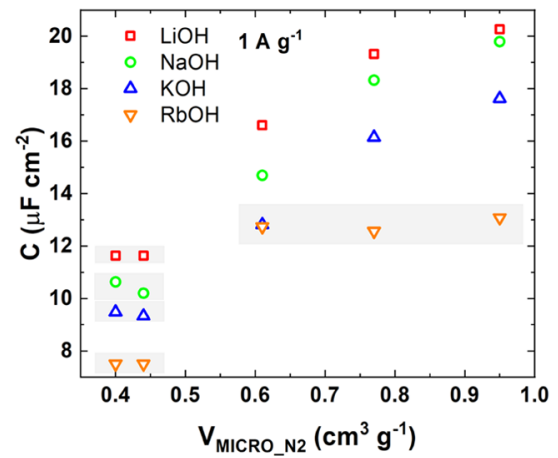

B

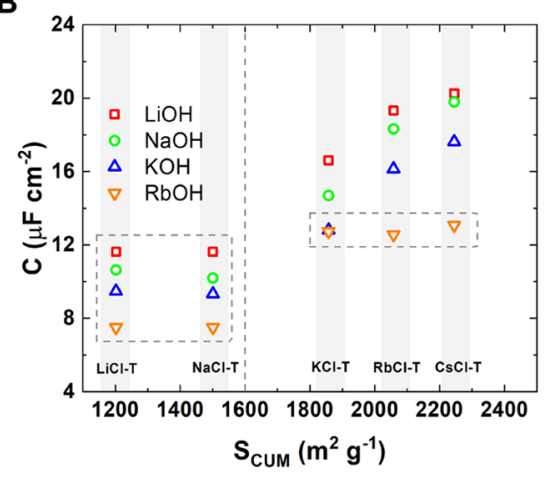

D

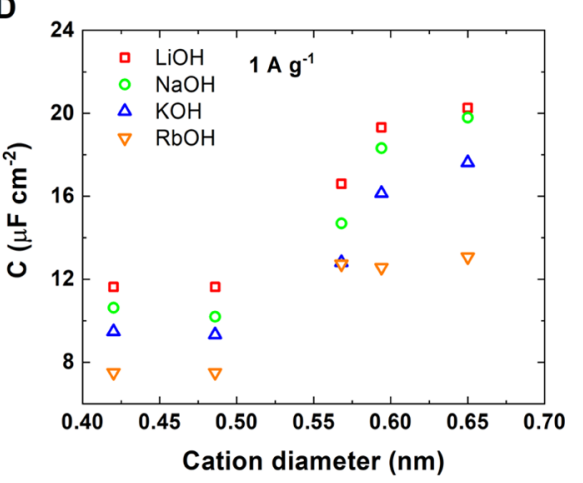

Figure 3. Correlations related to the texture of the carbon electrode material and its capacitance at $0.1 \mathrm{Ag}^{-1}:$ gravimetric capacitance as a function of the $S_{\text {CUM }}(\mathrm{a})$; specific capacitance as a function of the $S_{\text {CUM }}(\mathrm{b})$; specific capacitance as a function of micropore volume determined by $\mathrm{N}_{2}$ adsorption (c); and specific capacitance $v$ s. cation diameter (d).

do believe that the trend is not that pronounced because various cations exhibited different roles during the synthesis process (favorable graphitization process, various binding energies, or different hydration enthalpies leading to various dehydration extents). Although similar salts were used, their crystallographic structure was not the same, particularly that of $\mathrm{CsCl}$, which was different than those of the other salts and may have impacted the pore size and topology. According to Table $1, \mathrm{CsCl}$ has a bodycentered cubic structure (BCC), where $\mathrm{Cl}^{-}$anions occupied the eight corners of the cube, whereas its center was occupied by $\mathrm{Cs}^{+}$. Each $\mathrm{Cs}^{+}$cation was surrounded by $8 \mathrm{Cl}^{-}$anions and vice versa, giving rise to a coordination number of 8-8. The number of units of $\mathrm{Cs}^{+}$and $\mathrm{Cl}^{-}$per unit cell was one. In the case of the other salts, they all adopted the $\mathrm{NaCl}$ face-centered cubic (FCC) structure with cations placed at the corners and face centers while the $\mathrm{Cl}^{-}$anions were placed at the body center and edges. The coordination number was 6-6, and the unit cell was composed of 4 units of $\mathrm{Na}^{+}$and $\mathrm{Cl}^{-}$. The different arrangements of the anions and cations may impact the interactions with the carbon matrix.

Therefore, the complex cation-carbon texture interactions and different salt properties and structures were the reason for the nonlinear dependence between $\mathrm{L}_{0}$ and the cation size (Figure 2c). We did observe, however, an increase in the value with increasing cation size following a decrease in the hydration enthalpy (from $0.73 \mathrm{~nm}$ for $\mathrm{LiCl}-\mathrm{T}$ to $0.88 \mathrm{~nm}$ for CsCl-T). The cation type in the salt template mostly impacted the volume of void space in the carbon matrix, which was in the micropore range. However, their dehydration properties and their impact on the Pluronic F127 micellization process influenced the mesopore formation and volume.
The highest $V_{\text {MESO }}\left(0.37 \mathrm{~cm}^{3} \mathrm{~g}^{-1}\right)$ obtained for LiCl-T and $\mathrm{NaCl}-\mathrm{T}$ could be explained by the free space between stacked graphene-like sheets that was created due to the strong interaction of carbon with the cations leading to graphitization and mesopore creation (Figure $1 \mathrm{~b}-\mathrm{d}$ ). This might be related to the high hydration energy, 520 and $406 \mathrm{~kJ} \mathrm{~mol}^{-1}$ for $\mathrm{Li}^{+}$and $\mathrm{Na}^{+}$, respectively. For the other cations, it was $<325 \mathrm{~kJ} \mathrm{~mol}^{-1}$, such as for templated materials $\mathrm{KCl}-\mathrm{T}, \mathrm{RbCl}-\mathrm{T}$, and $\mathrm{CsCl}-\mathrm{T}$, which decreased and created comparable mesopore volumes (between 0.23 and $\left.0.19 \mathrm{~cm}^{3} \mathrm{~g}^{-1}\right) . \mathrm{NaOH}$ was also used in the synthesis to adjust the $\mathrm{pH}$ of the solution, and this was a key factor that allowed the creation of microporosity. ${ }^{23}$ Therefore, in the synthesis mixture, the studied cations were always in competition with $\mathrm{Na}^{+}$for either water molecules or for aromatic rings of the phloroglucinol-based phenolic resin. In such a case, $\mathrm{Li}^{+}$and $\mathrm{Na}^{+}$cations, which possessed a high hydration energy, were strongly hydrated, and cations with solvation shells participated in the synthesis process, affecting the formation of micelles and increasing the mesopore ratio. For $\mathrm{K}^{+}, \mathrm{Rb}^{+}$, and $\mathrm{Cs}^{+}$, which have a high atomic radius, the solvation shell might be removed quite easily, with little energetic cost. Therefore, their mesopore fraction seemed to be similar and affected by their hydration energy.

Figure $2 \mathrm{c}$ summarizes all parameters of the carbons affected to the same extent by the type/size of the cation used in the salt template process, i.e., the micropore volume, specific surface area, and $L_{0}$. All of these parameters were affected comparatively, and moreover, their correlation with the size of the solvated cation in the salt template was non-linear as expected from the literature review. The correlation coefficient (while considering the exponential coefficient) for the specific surface area and micropore volume is similar with a value of $R^{2}>0.9500$. The 
exponential fit for the $L_{0}$ data was not high $\left(R^{2}=0.7241\right)$; however, it was much higher than that for the linear relationship. We believe that the lack of a significant difference in $L_{0}$ for LiCl$\mathrm{T}, \mathrm{NaCl}-\mathrm{T}$, and $\mathrm{KCl}-\mathrm{T}$ was related to their hydration enthalpies, binding energies, and melting temperatures. All of these parameters are correlated and establish specific features of synthesized carbons.

To evaluate the microporosity of the materials, $\mathrm{CO}_{2}$ adsorption at $273 \mathrm{~K}$ was used to investigate the textural properties of the materials (Table 2 and Figure $2 \mathrm{~d}$ ); the goal was to find bottle-shaped micropores that may be formed due to micropore coalescence. The $V_{\text {MICRO }}$ determined by $\mathrm{CO}_{2}$ adsorption presented lower values as that evaluated by $\mathrm{N}_{2}$ adsorption and no specific trends with the size of the cation. The ultramicropores created during the salt templating process may be needed to reach high specific capacitance values. Regarding the synthesized material texture findings, it was found that the cation size directly influenced the micropore volume (the higher the cation size, the higher the micropore volume), which was in accordance with the specific surface area. The average micropore diameter seemed to correlate with this trend as well; however, here, the hydration enthalpy and binding energy played a crucial role, and therefore, for LiCl-T, NaCl-T, and $\mathrm{KCl}-\mathrm{T}$, no significant differences were observed. In aqueous solutions containing $\mathrm{Li}^{+}$and/or $\mathrm{Na}^{+}$, the ions were more likely to be in a hydrated state than being bare. Thus, they had a high affinity to water molecules and tended to be in a hydrated state. They were characterized by a strong hydration enthalpy (according to Table 1) due to their small ionic radii, so they were less susceptible to losing their hydration shell. In the initial solution during synthesis, $\mathrm{Li}^{+}$and $\mathrm{Na}^{+}$competed for their affinity to water molecules and phenolic resin aromatic rings. However, $\mathrm{K}^{+}$was more directed toward binding with the aromatic rings in the phenolic resin, different than $\mathrm{Li}^{+}$or $\mathrm{Na}^{+}$, but was still in a hydrated state at the same time. ${ }^{23}$ Moreover, hydration enthalpy somewhat regulates the mesopore volume. The mesopore fraction of the total pore volume was low for cations that were easy to dehydrate. The high mesopore fraction in the $\mathrm{LiCl}-\mathrm{T}$ and $\mathrm{NaCl}-\mathrm{T}$ materials might also have resulted from the $\mathrm{Li}^{+}$and $\mathrm{Na}^{+}$ having favorable bonding to the $-\mathrm{O}$ moieties in polyethylene oxide (PEO) blocks in Pluronic F127, which led to modifications during the micelle formation stage. These results seem to be in accordance with the micropore coalescence model, which also should impact the ultramicropore volume. The absence of a soft template (KCl-NT) mostly influenced the volume of the mesopores, proving that micropore creation was mostly due to cations, while the development of pores with a diameter of $>2 \mathrm{~nm}$ resulted mainly from the soft template, but the salt may impact their size/volume as well.

3.2. Electrochemical Characterization. 3.2.1. Influence of the Carbon Texture on the Specific Capacitance. Figure 3 combines various full-cell electrochemical performance/carbon texture correlations. Figure 3 a presents the correlation between the specific capacitance and cumulative surface area. A relationship can be observed , i.e., the capacitance increased as the cumulative surface area increased. The same correlation was found when considering the $S_{\mathrm{BET}}$ (Figure S2a, Supporting Information) instead of the $S_{\mathrm{CUM}}$. As the $S_{\mathrm{BET}}$ might overestimate the specific surface area, the $S_{\mathrm{CUM}}$ values were chosen for further analysis because they appeared to be more reliable.

A linear dependence was found for the $\mathrm{LiOH}, \mathrm{NaOH}$, and $\mathrm{KOH}$ electrolytic solutions $\left(R^{2}>0.9000\right)$ between the specific capacitance and specific surface area. However, $\mathrm{RbOH}$ did not follow this trend strictly, and it had a lower $R^{2}(0.8526)$. This might be related to the higher cation dimension (Table 1), which did not allow rubidium cations from the electrolytic solution to create the developed EDL when $S_{\mathrm{CUM}}<1600 \mathrm{~m}^{2} \mathrm{~g}^{-1}$. Thus, for the LiCl-T and $\mathrm{NaCl}-\mathrm{T}$ materials, steric hindrance between the electrolyte ions and pore size likely occurred. In Figure $3 \mathrm{~b}$, the specific capacitance is plotted against $S_{\mathrm{CUM}}$. No linear correlation appeared among the various electrolytes, and two regions could be designated with $S_{\text {CUM }}$ values $<1600$ and $>1600 \mathrm{~m}^{2} \mathrm{~g}^{-1}$. In the case of the LiCl-T and NaCl-T materials, their normalized specific capacitance was similar for the same electrolytic solutions. However, for samples $\mathrm{KCl}-\mathrm{T}, \mathrm{RbCl}-\mathrm{T}$, and $\mathrm{CsCl}-\mathrm{T}$, the specific capacitance increased at higher $S_{\mathrm{CUM}}$ values. The plausible scenario for that behavior is that the developed specific surface area $\left(1858 \mathrm{~m}^{2} \mathrm{~g}^{-1}\right.$ for KCl-T, $2058 \mathrm{~m}^{2} \mathrm{~g}^{-1}$ for $\mathrm{RbCl}-\mathrm{T}$, and $2245 \mathrm{~m}^{2} \mathrm{~g}^{-1}$ for $\mathrm{CsCl}-\mathrm{T}$ ) was capable of storing more ions than when there was a moderate $S_{\text {CUM }}\left(1202 \mathrm{~m}^{2} \mathrm{~g}^{-1}\right.$ for $\mathrm{LiCl}-\mathrm{T}$ and $1501 \mathrm{~m}^{2} \mathrm{~g}^{-1}$ for $\mathrm{NaCl}-\mathrm{T}$ ). For the $\mathrm{RbOH}$ electrolytic solution, two levels of specific capacitance were reached within the sets of all materials. We suspect that the rubidium diameter was too large to be adsorbed on the electrode surface to a greater extent. Most likely, if the carbon material reaches a sufficiently developed $S_{\text {CUM }}$, the amount of stored charge with $\mathrm{RbOH}$ should increase.

Therefore, we considered micropore volume (Figure $3 \mathrm{c}$ and Figure S2b) to verify whether our assumption concerning specific surface area accessibility is correct. Even though the micropore volume found by two different adsorbates $\left(\mathrm{N}_{2}\right.$ and $\mathrm{CO}_{2}$ ) differed, the observed trend for the gravimetric capacitance was the same. This resulted from the same micropore volume ratio between the samples when considering data for either $\mathrm{N}_{2}$ or $\mathrm{CO}_{2}$ adsorption (Table 1). For $\mathrm{RbOH}$, as previously observed for the $S_{\mathrm{CUM}}$, two levels of gravimetric capacitance can be distinguished. However, the rest of the electrolytic solutions revealed a good linear dependence on the micropore volume, with $R^{2}=0.9335(\mathrm{LiOH}), R^{2}=0.9621$ $(\mathrm{NaOH})$, and $R^{2}=0.9740(\mathrm{KOH})$. Interestingly, considering the gravimetric capacitance values, all electrolytes seemed to operate similarly (Figure 3a). Thus, only material texture parameters played a role and increased the specific capacitance among the samples. The electrode made of the LiCl-T material operating with $1 \mathrm{~mol} \mathrm{~L}^{-1} \mathrm{LiOH}$ electrolyte demonstrates the gravimetric capacitance of $124 \mathrm{~F} \mathrm{~g}^{-1}$, whereas the electrode based on the CsCl-T material operating with the same electrolytic solution has a capacitance of $216 \mathrm{~F} \mathrm{~g}^{-1}$. While considering gravimetric capacitance, one may notice that the smaller the cation in the electrolytic solution, the higher the gravimetric capacitance recorded for each material type separately. Therefore, cations, like $\mathrm{Li}^{+}$or $\mathrm{Na}^{+}$, are capable of penetrating carbon pores better than $\mathrm{K}^{+}$and $\mathrm{Rb}^{+}$when considering the normalized capacitance (Table 1). However, these cations underwent the dehydration process less favorably due to a higher hydration enthalpy.

Figure $3 \mathrm{~d}$ presents the dependence of the gravimetric capacitance as a function of cation diameter. A linear trend was found for all electrolytic solutions $\left(R^{2}>0.8400\right)$. Since the cations used during synthesis and in electrochemical solutions during electrochemical characterization were the same, this plot is related to the size of the cation used during synthesis. Generally, the larger the cation dimension that was used during synthesis, the higher the gravimetric capacitance of the system. The most significant difference among the specific capacitance values occurred for electrolytes containing the smallest cation 

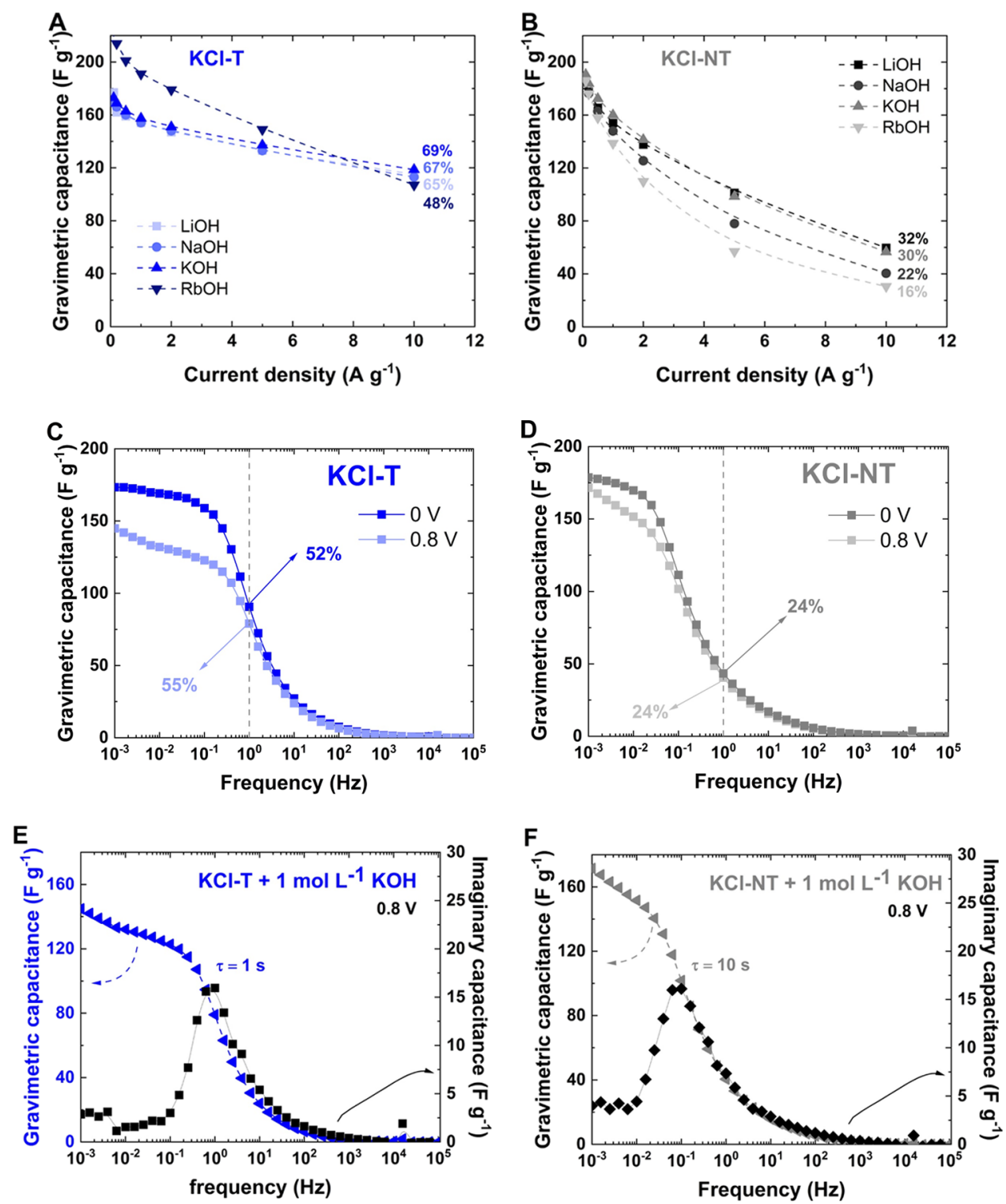

Figure 4. Comparison of KCl-T and KCl-NT materials: capacitance retention for various electrolytes calculated from galvanostatic charge/discharge curves for KCl-T (a); capacitance retention for various electrolytes calculated from galvanostatic charge/discharge curves for KCl-NT (b); capacitance $v s$. frequency for $\mathrm{KCl}-\mathrm{T}(\mathrm{c})$; capacitance $v$ s. frequency for $\mathrm{KCl}-\mathrm{NT}$ (d); time constant at $0.8 \mathrm{~V}$ for $\mathrm{KCl}_{-\mathrm{T}}$ with $1 \mathrm{~mol} \mathrm{~L}^{-1} \mathrm{KOH}(\mathrm{e})$; and time constant at $0.8 \mathrm{~V}$ for KCl-NT (f). Electrolyte: $1 \mathrm{~mol} \mathrm{~L}{ }^{-1} \mathrm{KOH}$.

( $\mathrm{LiOH}$ ) from $12 \mu \mathrm{F} \mathrm{cm}^{-2}$ (LiCl-T) up to $20 \mu \mathrm{F} \mathrm{cm}^{-2}$ (CsCl-T). The specific capacitance for the $\mathrm{RbOH}$ electrolytic solution ranged from 8 to $13 \mu \mathrm{F} \mathrm{cm}^{-2}$. It has to be considered that specific capacitance itself does not inform yet about carbon material pore size/ion size matching. Interestingly, for one material applied as the electrode, no detrimental differences may be found for a set of hydroxide solutions used as electrolytes. Thus, it seems that the electrolyte conductivity does not play a significant role (Table S1) as the conductivity of $1 \mathrm{~mol} \mathrm{~L}^{-1} \mathrm{LiOH}$ is $155 \mathrm{mS}$ $\mathrm{cm}^{-1}$, while that of $1 \mathrm{~mol} \mathrm{~L}^{-1} \mathrm{CsOH}$ is $218 \mathrm{mS} \mathrm{cm} \mathrm{cm}^{-1}$.

The overall cell performance results from both cation and anion adsorption/desorption at the electrode/electrolyte interfaces on the negative and positive electrodes, respectively. Considering the pore size distribution of the synthesized carbons (Figure 2b), all materials were suitable for effective hydroxide anion storage (with a radius of $0.110 \mathrm{~nm}$ ). Therefore, to diminish the anion impact on the charge storage mechanism, hydroxide electrolytic solutions were selected.
Furthermore, it is known that, during micropore penetration, ions undergo either a partial or total dehydration process, which strictly affects their effective diameter. ${ }^{50-56}$ Unfortunately, the use of an in situ measuring technique would enable a discussion about the actual sizes of the ions during EDL formation. As discussed in the previous section, the cation diameter affects the micropore volume as well as the gravimetric capacitance. The presented correlations demonstrated exponential or linear trends, which led to the conclusion that considering only the cation diameter in such deviations would explain these phenomena.

3.2.2. Influence of the Carbon Texture on the Rate Capability. Because the micro- and mesopore volumes varied among the set of synthesized soft-salt templated materials ( $\mathrm{LiCl}-$ $\mathrm{T}, \mathrm{NaCl}-\mathrm{T}, \mathrm{KCl}-\mathrm{T}, \mathrm{RbCl}-\mathrm{T}$, and CsCl-T), it was impossible to draw any reliable conclusions considering only the mesopore influence on the EC performance. The charge retention, resulting from the mesopore volume, is estimated as a crucial 

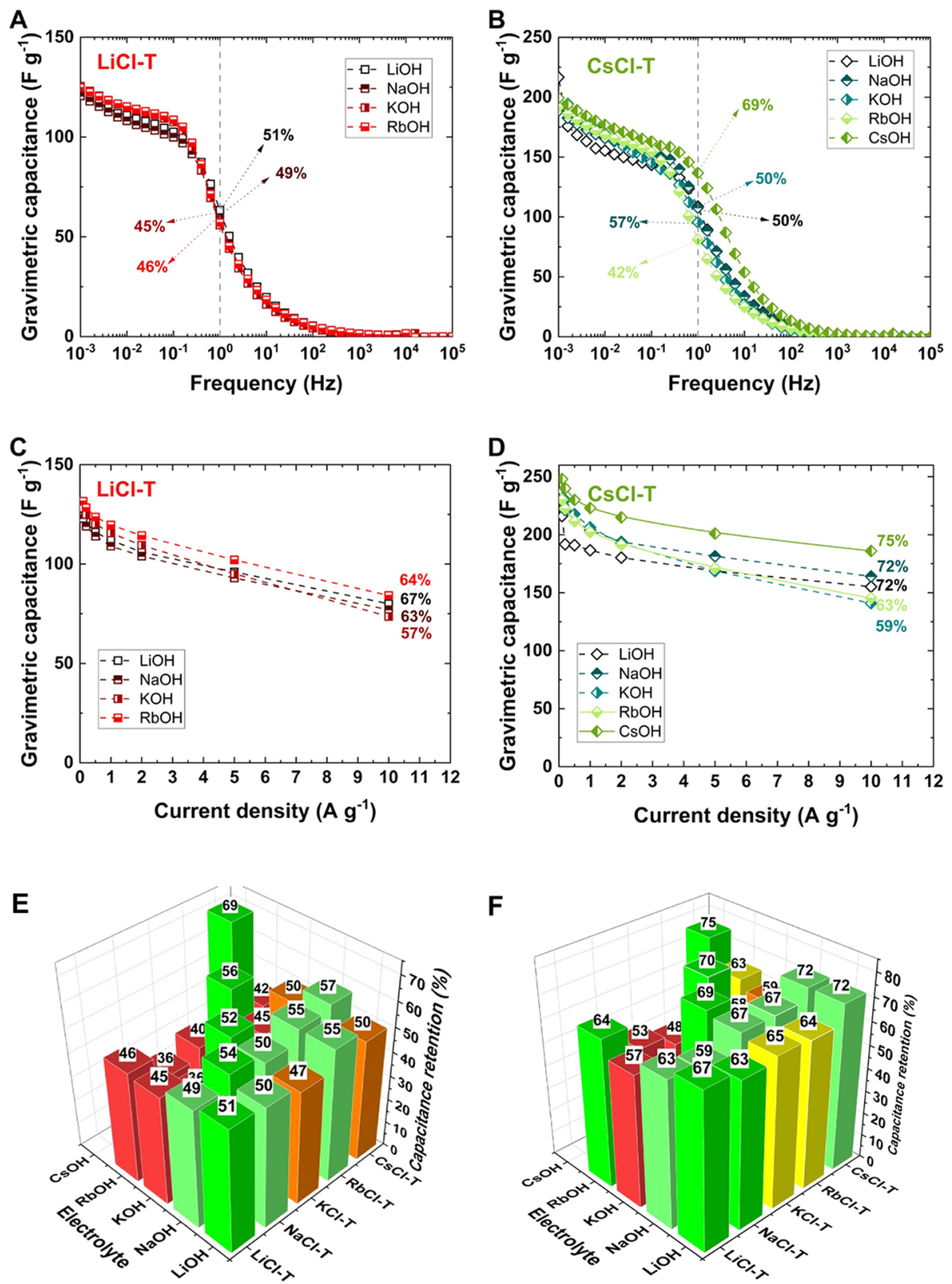

Figure 5. Influence of the carbon texture on the pore size/ion size matching. Capacitance vs. frequency at $0.8 \mathrm{~V}$ for $\mathrm{LiCl}-\mathrm{T}$ (a) and CsCl-T (b) with 1 mol L ${ }^{-1} \mathrm{MeOH}$ (where $\mathrm{Me}=\mathrm{Li}^{+}, \mathrm{Na}^{+}, \mathrm{K}^{+}, \mathrm{Rb}^{+}, \mathrm{Cs}^{+}$). Capacitance $v$ s. current density for LiCl-T (c) and CsCl-T (d) with $1 \mathrm{~mol} \mathrm{~L} \mathrm{~L}^{-1} \mathrm{MeOH}$ (where $\mathrm{Me}$ $\left.=\mathrm{Li}^{+}, \mathrm{Na}^{+}, \mathrm{K}^{+}, \mathrm{Rb}^{+}, \mathrm{Cs}^{+}\right)$. Capacitance retention with color mapping (green is the highest value and red is the lowest value) for all synthesized carbons from impedance spectroscopy at $0.8 \mathrm{~V}$ (e) and from galvanostatic charge/discharge (f).

parameter for high-power applications. Therefore, an additional sample without Pluronic F127 was prepared and was labeled as KCl-NT. A comparison between the KCl-T and KCl-NT XRD patterns (Figure S3a), Raman spectra (Figure S3b), and adsorption isotherms (Figure S3c) is shown in the Supporting Information. The structure analysis (XRD and Raman) demonstrated that the samples had similar structural properties. Thus, the soft template did not change the structural properties of the synthesized materials. However, both the salt template $(\mathrm{KCl})$ and soft template influenced the material texture. The micropore volume was similar for $\mathrm{KCl}-\mathrm{T}\left(0.61 \mathrm{~cm}^{3} \mathrm{~g}^{-1}\right)$ and KCl-NT $\left(0.64 \mathrm{~cm}^{3} \mathrm{~g}^{-1}\right)$. The same trend was observed for the $S_{\text {CUM }}$, which was $1673 \mathrm{~m}^{2} \mathrm{~g}^{-1}$ for KCl-T and $1732 \mathrm{~m}^{2} \mathrm{~g}^{-1}$ for KCl-NT. The only large difference was noticeable for mesopore volume, which was $0.23 \mathrm{~cm}^{3} \mathrm{~g}^{-1}$ for $\mathrm{KCl}-\mathrm{T}$ (sample synthesized in the presence of soft template) and significantly lower, 0.06 $\mathrm{cm}^{3} \mathrm{~g}^{-1}$ for KCl-NT.

Figure $4 a, b$ presents the specific capacitance as a function of the current density. Both samples had similar specific capacitances at $0.1 \mathrm{~A} \mathrm{~g}^{-1}$, i.e., $173 \mathrm{~F} \mathrm{~g}^{-1}$ for $\mathrm{KCl}-\mathrm{T}$ with $\mathrm{KOH}$ and $191 \mathrm{~F} \mathrm{~g}^{-1}$ for $\mathrm{KCl}-\mathrm{NT}$ with $\mathrm{KOH}$. This result can be linked to a similar micropore volume that allowed the storage of a comparable amount of charge. However, at $10 \mathrm{Ag}^{-1}$, the specific capacitance remaining for $\mathrm{KCl}-\mathrm{T}$ was $60 \%$ for all studied electrolytes (Figure 4a), while for KCl-NT, it was $<35 \%$ (Figure 4b). At first glance, we can attribute the better capacitance retention for $\mathrm{KCl}-\mathrm{T}$ to a large number of mesopores ( 0.23 vs. $\left.0.06 \mathrm{~cm}^{3} \mathrm{~g}^{-1}\right)$, which is the only main difference between these two materials. The absence of a soft template decreased the mesopores volume from $27 \%$ to $9 \%$ of the total pore volume. 
Figure $4 \mathrm{c}, \mathrm{d}$ compares the time response of the micro/ mesoporous (KCl-T) and only microporous (KCl-NT) carbons (in $1 \mathrm{~mol} \mathrm{~L}^{-1} \mathrm{KOH}$ electrolytic solution as an example). Although the initial specific capacitance of the KCl-T-based system was just slightly smaller than that of the KCl-NT-based system in the impedance measurement, the specific capacitance curve had a different profile. The capacitance retention at $1 \mathrm{~Hz}$ decreased from $52 \%$ for $\mathrm{KCl}-\mathrm{T}$ to $24 \%$ for $\mathrm{KCl}-\mathrm{NT}$ (i.e., by $50 \%)$. These results are in accordance with the change in the mesopore volume over the total pore volume in the carbons. In the $\mathrm{KCl}-\mathrm{T}$ material, the mesopore volume remained at $27 \%$ of the total pore volume, while in the KCl-NT material, it was only $9 \%$. The time constant calculated for a system based on KCl-T with $1 \mathrm{~mol} \mathrm{~L}^{-1} \mathrm{KOH}$ was much shorter that for the KCl-NT system, i.e., $1 \mathrm{~s}$ vs. $10 \mathrm{~s}$ (Figure 4e,f), resembling the higher mesopore content in $\mathrm{KCl}-\mathrm{T}$ than in the $\mathrm{KCl}-\mathrm{NT}$ material. This parameter is known as dielectric relaxation, which is a characteristic of the whole system, which is nicely correlated with the amount of mesopores present in the electrode material. The presence of pore tunnels for ion transport resulting in fast electrode surface repolarization could be qualitatively proven at high current regimes. Furthermore, the time constant of a system is a reliable parameter if the comparison between the two materials is driven. ${ }^{57}$ Comparing the two systems based on $\mathrm{KCl}-$ $\mathrm{T}$ and KCl-NT electrode materials, it is shown that a combination of both micro- and mesopores in the electrode material played a crucial role in the electrochemical performance, which is important from the application point of view, especially when discussing the number of charges stored during the fast charge/discharge process. Micropores themselves provide the developed surface for charge adsorption; however, they do not support ions fluxes during fast repolarization processes. Additionally, the abovementioned results complement other literature studies concerning the mesopore role in the charge storage mechanism, especially regarding $\mathrm{CNTs}^{14,58}$ and activated carbons. ${ }^{59-62}$

3.2.3. Influence of the Ion/Pore Size Matching on the Electrochemical Performance. Ion/pore matching is the term that combines both ion/pore size, ion/pore shape, and ion/ carbon affinity dependences. In Figure $5 \mathrm{a}, \mathrm{b}$, data from impedance spectroscopy recorded at $0.8 \mathrm{~V}$ are presented for $\mathrm{LiCl}-\mathrm{T}$ and $\mathrm{CsCl}-\mathrm{T}$ as the most diverse materials. Additionally, capacitance vs. current density for $\mathrm{LiCl}-\mathrm{T}$ and $\mathrm{CsCl}-\mathrm{T}$ is depicted in Figure 5c and Figure 5d, respectively. Corresponding constant current charge/discharge profiles are depicted in Figure S4a-f (Supporting Information). The capacitance retention for all synthesized materials combined with a set of hydroxide solutions is presented in Figure 5e from impedance studies at $0.8 \mathrm{~V}$ and Figure $5 \mathrm{f}$ from galvanostatic charge/ discharge measurements.

For each templated carbon, a set of hydroxide electrolytic solutions was used to disclose any correlation between their electrochemical performance and textural characteristics. First, the specific capacitance is a characteristic of a material that is independent of the type of hydroxide electrolytic solution. However, as previously discussed, the gravimetric capacitance is strictly correlated with the size of cations present in the electrolytic solution, so the system with the $\mathrm{LiOH}$-based electrolyte achieved the highest gravimetric capacitance for all synthesized carbons. Thus, a discussion of the ion size/pore size matching of carbon materials considering only the specific or gravimetric capacitance results is not sufficient. Therefore, impedance spectroscopy studies at 0 and $0.8 \mathrm{~V}$ together with galvanostatic charge/discharge measurements were also implemented. For the LiCl-T material (Figure 5a), a very satisfactory capacitive performance was observed, i.e., a plateau was present in the low-frequency range up to $200 \mathrm{mHz}$. This result showed that, while increasing the frequency of the charge/ discharge cycling from 0.001 to $0.2 \mathrm{~Hz}$, the number of charges stored in the system was almost constant. Therefore, differences in the capacitance retention were rather minor. The capacitance retention calculated from impedance studies is based on the specific capacitance ratio at $1 \mathrm{~Hz}$ and the initial capacitance ratio at $1 \mathrm{mHz}$. The trend for capacitance retention for the ECs based on the LiCl-T electrode material was observed for electrolytes to be in the following order: $\mathrm{LiOH}>\mathrm{NaOH}>\mathrm{RbOH}>\mathrm{KOH}$ $(51 \%>49 \%>46 \%>45 \%)$. The capacitance response as a function of the applied frequency for the material with the most developed specific surface area, CsCl-T, is presented in Figure $5 \mathrm{~b}$. As discussed previously, the high specific capacitance value was noticeable. Moreover, the highest capacitance retention of $59 \%$ was recorded when cations in the electrolytic solution combined with those used during synthesis (CsCl-T with $\mathrm{CsOH}$ ). Thus, the pore size/ion size matching was valid for both more graphitic/less porous $(\mathrm{LiCl})$ and less graphitic/more porous $(\mathrm{CsCl})$ materials. Figure 5 e summarizes the data for all materials, i.e., LiCl-T, NaCl-T, KCl-T, RbCl-T, and CsCl-T. A clear trend that the best capacitance retention was recorded for the electrolytes with the corresponding cation to the one used during synthesis. For all electrodes, utilization of larger cations in the electrolyte than that used during synthesis decreased the capacitance retention significantly. This might be related to steric hindrance effects because, for the same micropore volume, larger ions generated more steric hindrance for each other. Additionally, for the EC based on LiCl-T, the specific capacitance retention for $\mathrm{LiOH}$ was $51 \%$, for $\mathrm{NaCl}-\mathrm{T}$ with $\mathrm{NaOH}$ it was $54 \%$, for $\mathrm{KCl}-\mathrm{T}$ with $\mathrm{KOH}$ it was $52 \%$, for $\mathrm{RbCl}-\mathrm{T}$ with $\mathrm{RbOH}$ it was $56 \%$, and for $\mathrm{CsCl}-\mathrm{T}$ with $\mathrm{CsOH}$ it was $69 \%$ (Figure 5e), which shows that, upon increasing the carbon porosity, the capacitance retention increased as the ions found it difficult to escape the micropores. Nonetheless, such unfavorable processes (steric hindrance) seemed to benefit the charge storage process.

Furthermore, these results were verified not only by impedance spectroscopy but also by galvanostatic charging/ discharging (Figure 5c,d,f and Figure S4). This technique is purely quantitative, which allows precise specific capacitance values to be calculated. Therefore, it was important to verify the pore size/ion size matching by this technique. At first glance, it was noticeable that the capacitance retention increased when considering $0.1 \mathrm{~A} \mathrm{~g}^{-1} / 1 \mathrm{~A} \mathrm{~g}^{-1}$ than $1 \mathrm{mHz} / 1 \mathrm{~Hz}$. This result was strictly related to the time domain of those processes as the discharge time at $1 \mathrm{~A} \mathrm{~g}^{-1}$ was higher than at $1 \mathrm{~Hz}$; it was $3.0 \mathrm{~s}$ for $\mathrm{LiCl}-\mathrm{T}$ with $\mathrm{LiOH}, 2.8 \mathrm{~s}$ for $\mathrm{NaCl}-\mathrm{T}$ with $\mathrm{NaOH}, 4.7 \mathrm{~s}$ for $\mathrm{KCl}-\mathrm{T}$ with $\mathrm{KOH}, 6.2 \mathrm{~s}$ for $\mathrm{RbCl}-\mathrm{T}$ with $\mathrm{RbOH}$, and $7.5 \mathrm{~s}$ for CsCl-T with $\mathrm{CsOH}$. However, it can be seen that capacitance retention is in accordance with the data evaluated from impedance spectroscopy. The LiCl-T capacitance retention from the galvanostatic charge/discharge measurement (Figure 5c) followed the order of $\mathrm{LiOH}(67 \%)>\mathrm{RbOH}(64 \%) \approx \mathrm{NaOH}$ $(63 \%)>\mathrm{KOH}(57 \%)$. However, the rate handling did not drop significantly when a larger cation was present in the electrolytic solution than the one used during synthesis, i.e., $\mathrm{Rb}^{+}$. For the $\mathrm{CsCl}-\mathrm{T}$ material, the trend was in the order of (Figure $5 \mathrm{~d}$ ) $\mathrm{CsOH}(75 \%)>\mathrm{LiOH}(72 \%)>\mathrm{NaOH}(72 \%)>\mathrm{RbOH}(63 \%)>$ $\mathrm{KOH}(59 \%)$. The rate handling increased for more porous 
A

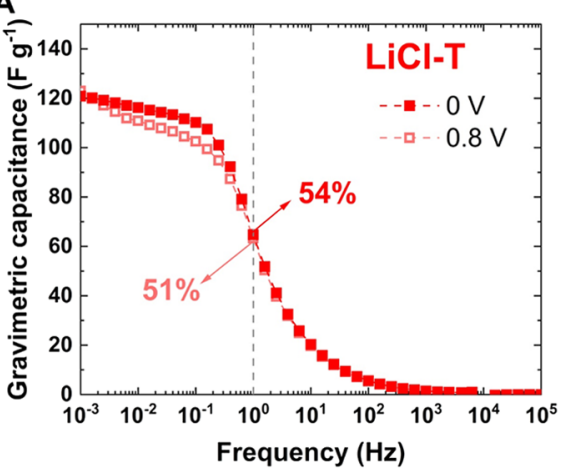

C

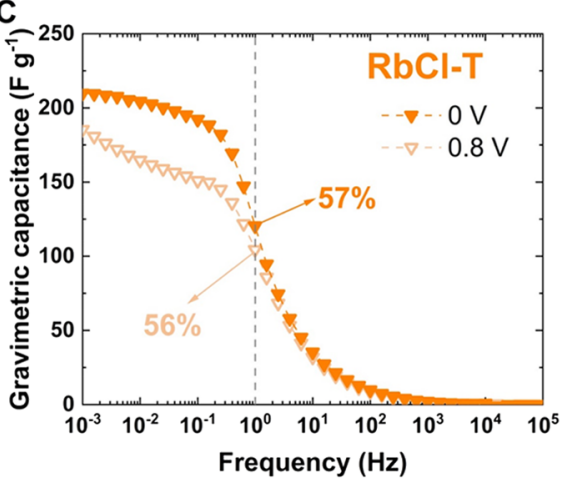

B

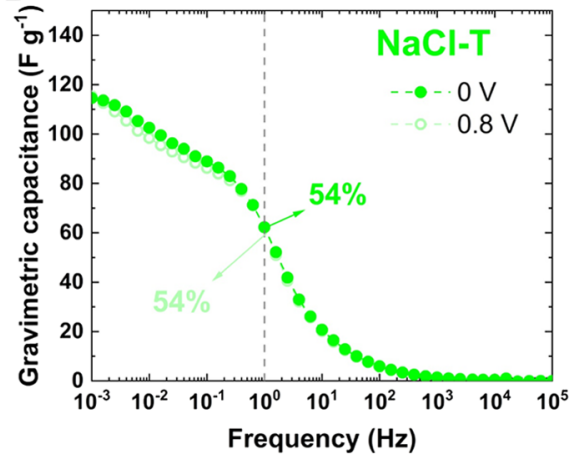

D

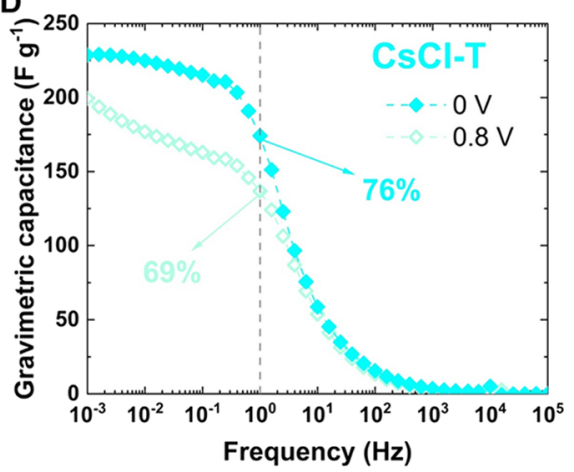

Figure 6. Gravimetric capacitance $v$ s. frequency recorded at 0 and $0.8 \mathrm{~V}$ for $\mathrm{LiCl}-\mathrm{T}$ with $1 \mathrm{~mol} \mathrm{~L}{ }^{-1} \mathrm{LiOH}(\mathrm{a}) ; \mathrm{NaCl}-\mathrm{T}$ with $1 \mathrm{~mol} \mathrm{~L}{ }^{-1} \mathrm{NaOH}(\mathrm{b}) ; \mathrm{RbCl}-$ $\mathrm{T}$ with $1 \mathrm{~mol} \mathrm{~L}^{-1} \mathrm{RbOH}$ (c); and CsCl-T with $1 \mathrm{~mol} \mathrm{~L}^{-1} \mathrm{CsOH}$ (d).

materials, as shown in the flattened specific capacitance curves over the applied current density. All materials operating with 1 mol L ${ }^{-1} \mathrm{KOH}$ electrolyte reveal moderate rate handling, which indicates that this cation is strongly solvated and has a strong affinity to carbon. It might be a hindrance for the charge storage process during high current loads. Moreover, the overall trend for carbon materials can be seen in samples with the peculiar coupling of the cation during synthesis and in the electrolyte for electrochemical tests (Figure 5f). A similar steric effect might be observed, however, to a lesser extent during a galvanostatic charge/discharge measurement than in an impedance study. When a larger cation is present in the electrolytic solution than the one used during synthesis, a decrease in the capacitance retention is observed. It is believed that mild differences between impedance and galvanostatic studies resulted from different time domains.

As an example, let us discuss the $\mathrm{KCl}-\mathrm{T}$ carbon material in detail. The $\mathrm{Rb}^{+}$hydrated cation $(0.594 \mathrm{~nm}$, Table 1$)$ was too large to penetrate the KCl-T-based electrode material deeply (the average pore size $L_{0}=0.68 \mathrm{~nm}$ and $V_{\text {MICRO }}=0.61 \mathrm{~cm}^{3} \mathrm{~g}^{-1}$, as shown in Table 2), and the capacitance retention for this material decreased significantly (69\% for $1 \mathrm{~mol} \mathrm{~L}^{-1} \mathrm{KOH}$ to $48 \%$ for $1 \mathrm{~mol} \mathrm{~L}^{-1} \mathrm{RbOH}$ ). Most likely, we can assume the same mechanism as presented in the literature, ${ }^{35}$ where the diameter of the pores did not allow the formation of EDLs on either side of the pore walls due to steric hindrance with the hydration shell and ions present in the micropore volume. Hence, the EDL was formed only on one pore wall, causing a decrease in the specific capacitance. For all synthesized carbons, the average maximum rate capability was $>51 \%$ during electrochemical impedance spectroscopy and $>58 \%$ for all galvanostatic charging/ discharging measurements. These results are in accordance with the values found for activated porous carbons, where it might vary from 30 to $65 \%$, depending on the electrolyte selected. 5,63,64 This proves that the soft-salt templated carbons are competitive with activated carbons. Additionally, the highest capacitance retention recorded among all synthesized carbons was equal to $75 \%$ (galvanostatic charge/discharge) and $69 \%$ (electrochemical impedance spectroscopy) for CsCl-T coupled with $\mathrm{CsOH}$. This rate capability value is high compared to those in other literature reports; ${ }^{65-68}$ this is especially true when discussing high-power rates calculated from cyclic voltammetry tests and not from quantitative electrochemical measurements, such as constant current charge/discharge or impedance spectroscopy at various voltages, or when comparing it to a sophisticated electrode material design. One needs to bear in mind also that it is much easier to maintain a moderate amount of charge at the electrode/electrolyte interface. When the specific surface area is developed, diffusion of ions plays an important role influencing rate handling. Moreover, as shown in Figure 5e,f, there was no strict correlation between the electrolytic solution conductivity (Table S1 in the Supporting Information) and its capacitance retention. Therefore, the only explicit reason for high capacitance retention, when the same cation is used during synthesis and in the electrolytic solution, is the pore size/pore shape and ion size matching. Moreover, it might be assumed that cations from electrolytic solutions revealing the same binding energy as that used during synthesis have a specific attraction to a carbon aromatic ring. Therefore, it is more favorable to stay adsorbed on the electrode surface than on other ionic species. Such a phenomenon, visible either from impedance studies or galvanostatic charge/discharge, has not been previously discussed and displayed in the literature.

3.2.4. Influence of the Carbon Structure on the Electrochemical Performance. To evaluate the stability of the electrode material, impedance spectroscopy in the frequency range from $100 \mathrm{kHz}$ to $1 \mathrm{mHz}$ was recorded at 0 and $0.8 \mathrm{~V}$. Therefore, not only the stability at high voltage but also the 
behavior of the material during electrochemical operation and its reaction to voltage stress were considered. To study the electrode structure influence on the electrochemical behavior, only selected electrolytes (Figure 6) with cations corresponding to those matching the carbon one ( $\mathrm{LiCl}-\mathrm{T}$ with $\mathrm{LiOH}$ and $\mathrm{NaCl}-$ $\mathrm{T}$ with $\mathrm{NaOH}$ ) are presented.

Figure 6 shows the specific capacitance $v$ s. frequency at $0.8 \mathrm{~V}$ for $\mathrm{LiCl}-\mathrm{T}, \mathrm{NaCl}-\mathrm{T}, \mathrm{RbCl}-\mathrm{T}$, and $\mathrm{CsCl}-\mathrm{T}$ (for $\mathrm{KCl}-\mathrm{T}$, the data is depicted in Figure 4c). All related Nyquist plots are presented in Figure S5a-e (Supporting Information). All studied ECs at $0 \mathrm{~V}$ demonstrate good charge propagation and fast charging/ discharging kinetics. Nyquist plots are perpendicular to the axis representing a real part of impedance $(\mathrm{OX})$ over the whole frequency range $(100 \mathrm{kHz}$ to $1 \mathrm{mHz})$. When the selected voltage is applied $(0.8 \mathrm{~V})$, the curves deviate from ideal electric doublelayer performance in the low-frequency region. For the highfrequency region, Nyquist plots are overlapping for both studied voltages (inset graphs). Moreover, it is worth highlighting that the recorded Nyquist plots resemble nearly ideal EDL performance. They can be divided into two main regions, socalled Warburg region, with the curve tilted by a $45^{\circ}$ angle, and electric double-layer formation, with the curve perpendicular to OX axis. The Warburg element demonstrates the presence of a diffusion process, which in ECs is attributed to the electrolyte ion diffusion into the pores. No semi-circle in the high-frequency region is observed for all synthesized materials, proving that capacitance and resistance are connected in series.

Increasing the size of the cation in the salt template increased its specific surface area and, as a result, the specific capacitance. $\mathrm{LiCl}-\mathrm{T}$ reveals a specific capacitance of $121 \mathrm{~F} \mathrm{~g}^{-1}$ at $1 \mathrm{mHz}$ (recorded at $0 \mathrm{~V}$ ), whereas it was $115 \mathrm{~F} \mathrm{~g}^{-1}$ for $\mathrm{NaCl}-\mathrm{T}, 173 \mathrm{~F}$ $\mathrm{g}^{-1}$ for KCl-T (Figure 4c), $210 \mathrm{~F} \mathrm{~g}^{-1}$ for $\mathrm{RbCl}-\mathrm{T}$, and $229 \mathrm{~F} \mathrm{~g}^{-1}$ for CsCl-T. However, concerning the stability of the materials, an opposite trend was observed with an increase in the cation size, which led to less graphitic materials due to their lower binding energy. The highest share of stacked graphitic-like structures (alignments of stacked graphene-like layers) was found for the LiCl-T material, which decreased with decreasing binding energy as follows: LiCl-T $>\mathrm{NaCl}-\mathrm{T}>\mathrm{KCl}-\mathrm{T}>\mathrm{RbCl}-\mathrm{T}$ $>\mathrm{CsCl}-\mathrm{T}$. RbCl-T and $\mathrm{CsCl}-\mathrm{T}$ had a highly disordered structure, equivalent to that of a highly porous texture.

The capacitance retention at $0 \mathrm{~V}$ was similar for all carbon materials, i.e., it was 54\% for $\mathrm{LiCl}-\mathrm{T}, 54 \%$ for $\mathrm{NaCl}-\mathrm{T}$, $55 \%$ for $\mathrm{KCl}-\mathrm{T}, 57 \%$ for $\mathrm{RbCl}-\mathrm{T}$, and, interestingly, $76 \%$ for $\mathrm{CsCl}-\mathrm{T}$, as discussed in the previous section. Therefore, the various structures did not influence this parameter; instead, the distinct textural parameters had an impact. However, the main difference among the samples may be observed when comparing the capacitance behavior at 0 and $0.8 \mathrm{~V}$. Hence, small cations induced more graphitic materials ( $\mathrm{LiCl}-\mathrm{T}$ and $\mathrm{NaCl}-\mathrm{T}$ ), and in such cases, the curves overlapped at low and high voltage stress. This means that their electrochemical performance was maintained, i.e., it was constant over a wide range of voltages. As there was no large volume of micropores penetrated by the ions $\left(0.40 \mathrm{~cm}^{3} \mathrm{~g}^{-1}\right.$ for $\mathrm{LiCl}-\mathrm{T}$ and $0.44 \mathrm{~cm}^{3} \mathrm{~g}^{-1}$ for $\left.\mathrm{NaCl}-\mathrm{T}\right)$ and a high volume of easily accessible mesopores $\left(0.37 \mathrm{~cm}^{3} \mathrm{~g}^{-1}\right.$ for $\mathrm{LiCl}-\mathrm{T}$ and $0.37 \mathrm{~cm}^{3} \mathrm{~g}^{-1}$ for $\mathrm{NaCl}-\mathrm{T}$ ), all of the structures were utilized to the same extent for EDL formation at 0 and $0.8 \mathrm{~V}$. For $\mathrm{KCl}-\mathrm{T}, \mathrm{RbCl}-\mathrm{T}$, and $\mathrm{CsCl}-\mathrm{T}$, which were less graphitic in nature, the specific capacitance profiles decreased when the spectra are obtained at $0.8 \mathrm{~V}$.

Noticeably, despite the specific capacitance profile change between 0 and $0.8 \mathrm{~V}$, the capacitance retention was rather stable for the $\mathrm{KCl}-\mathrm{T}$, RbCl-T, and CsCl-T samples (from $55 \%$ at $0 \mathrm{~V}$ to $52 \%$ at $0.8 \mathrm{~V}$ for $\mathrm{KCl}-\mathrm{T}$, from $57 \%$ to $56 \%$ for $\mathrm{RbCl}-\mathrm{T}$, and from $75 \%$ to $69 \%$ for $\mathrm{CsCl}-\mathrm{T}$ ). This resulted from the smaller initial specific capacitance values recorded during the slow charge/ discharge process at $0.8 \mathrm{~V}$. For more ordered materials ( $\mathrm{LiCl}-\mathrm{T}$ and $\mathrm{NaCl}-\mathrm{T}$ ), between 0 and $0.8 \mathrm{~V}$, no difference was observed either in the capacitance values or in the capacitance retention or capacitance profiles. For LiCl-T in the range of low frequencies, a plateau at a specific capacitance was observed, indicating very good stability and EDL performance without the presence of any side reactions. For $\mathrm{NaCl}-\mathrm{T}$ carbon, by increasing the frequency, the specific capacitance decreased linearly, and the two spectra $(0$ and $0.8 \mathrm{~V}$ ) overlapped, suggesting that they did not exhibit a perfect EDL behavior. Because this sample had similar texture parameters to those of LiCl-T (like the micro- and mesopore volumes), we believe that it resulted from either different pore shapes or an even weaker ion attraction to the carbon surface. Nonetheless, carbons with a more ordered structure (Li- and Na-based carbons) were very durable and did not change their properties drastically when a voltage was applied. This is a very interesting feature for these carbons since it is usually difficult to obtain materials that combine a high porosity and graphitic domains. For highly porous samples, the specific capacitance profiles for ECs based on $\mathrm{KCl}-\mathrm{T}, \mathrm{RbCl}-\mathrm{T}$, and $\mathrm{CsCl}-\mathrm{T}$ recorded at $0.8 \mathrm{~V}$ deviated slightly from the ideal EDL performance as a slight slope was observed up to $1 \mathrm{~Hz}$, and the ideal spectra were recorded at $0 \mathrm{~V}$. A well-maintained plateau was observed along the high specific capacitance in the low-frequency region. This led to a conclusion that, in the porous structures, ion transport was diminished when a voltage was applied. It caused trapping of ions inside the pores, which led to a decrease in the overall specific capacitance, or, due to the presence of the external electric field, ions became agglomerated, creating clusters with a lower mobility. Even though the pore shape was assumed to be more open than in the case of LiCl-T or NaCl-T (bottle-like shape due to micropore coalescence), their high volume seemed to create a steric hindrance for ionic transport. Impedance spectroscopy is a valuable approach to study the charge propagation of the material in electrochemical capacitors. It provides information about the structure and porosity. Interestingly, as the material exhibited a highly developed surface area (KCl-T, RbCl-T, and CsCl-T), this apparently reduced their ability to maintain charge over the applied voltage. However, the number of stored charges was higher than in the case of materials with less developed specific surface areas. Samples containing stacked graphitic-like fractions ( $\mathrm{LiCl}-\mathrm{T}$ and $\mathrm{NaCl}-\mathrm{T}$ ) were more stable in the low-frequency ranges at various voltages. However, what is surprising is that the graphitized structure did not influence the performance at all in the high-frequency range as the capacitance retention at $1 \mathrm{~Hz}$ for all studied materials was similar, i.e., $\sim 55 \%$, and decreased when a higher frequency was applied.

Further, the long-term stability has been investigated by a galvanostatic charge/discharge method, so-called cycling protocol, presented in Figure S6 (Supporting Information). The results demonstrate that the electrodes with a more graphitic structure perform better: ECs with $\mathrm{NaCl}-\mathrm{T}$ electrodes operating with $1 \mathrm{~mol} \mathrm{~L}^{-1} \mathrm{NaOH}$ deliver more than 10,000 cycles with a capacitance retention of $87 \%$. ECs with $\mathrm{CsCl}$-T electrodes operating with $1 \mathrm{~mol} \mathrm{~L}^{-1} \mathrm{CsOH}$ reached the end-of-life criterion ( $80 \%$ of initial capacitance) after 8000 charge/discharge cycles. It seems that more developed porosity $(\mathrm{CsCl}-\mathrm{T})$ is prone to the 
detrimental structural changes during ion transport from and into the micropores.

\section{CONCLUSIONS}

It was shown that a gradual increase in the salt-template cation size (from $\mathrm{Li}^{+}$to $\mathrm{Cs}^{+}$) led to an increase in the carbon specific surface area and to pore size broadening. From a structural point of view, the opposite behavior was observed: the smaller cations $\left(\mathrm{Li}^{+}, \mathrm{Na}^{+}\right)$, having a higher binding energy to the carbon matrix, led to the development of graphitized domains in the carbon material. Therefore, the electrochemical performance was impacted by both the texture and the structure of the materials. First, a correlation between the specific capacitance of soft-salt templated carbons with $\mathrm{LiOH}, \mathrm{NaOH}, \mathrm{KOH}, \mathrm{RbOH}$, and $\mathrm{CsOH}$ electrolytes was obtained, and the values were placed in the following order: LiCl-T $<\mathrm{NaCl}-\mathrm{T}<\mathrm{KCl}-\mathrm{T}<\mathrm{RbCl}-\mathrm{T}<$ $\mathrm{CsCl}-\mathrm{T}$, which corresponded to the specific surface area and micropore volume evolution with the cation size increment. Second, it was demonstrated that the synthesized carbons provided the highest capacitance retention (both for constant current charge/discharge and impedance studies) when there was coupling of the cation used during synthesis to the cation present in the electrolyte. Therefore, cations from electrolyte/ pore size matching were observed for the first time (e.g., LiCl-T with $\mathrm{LiOH}$ and $\mathrm{CsCl}-\mathrm{T}$ with $\mathrm{CsOH}$ ). The importance of the mesoporosity was demonstrated from a comparison of two materials that contained the same microporosity but distinct mesoporosity. The mesoporosity provided tunnels for the transport of ions before deep pore penetration, affording a high capacitance retention during galvanostatic charge/discharge testing, i.e., $69 \%$ for $\mathrm{KCl}-\mathrm{T}$ vs. $30 \%$ for $\mathrm{KCl}-\mathrm{NT}$.

Other than the carbon texture (surface area and pore size), the structure (degree of graphitization) proved to have an impact on the performance. Namely, LiCl-templated carbon, which had the most graphitic structure, had a very good rate capability and stability at elevated voltages $(0.8 \mathrm{~V})$, as proven by electrochemical impedance spectroscopy. In contrast, CsCl-T, which had the most porous texture $\left(S_{\mathrm{CUM}}=2245 \mathrm{~m}^{2} \mathrm{~g}^{-1}\right)$, had the highest gravimetric capacitance $\left(248 \mathrm{~F} \mathrm{~g}^{-1}\right.$ at $1 \mathrm{~A} \mathrm{~g}^{-1}$ with $1 \mathrm{~mol}$ $\mathrm{L}^{-1} \mathrm{CsOH}$ ) but a lower capacity retention due to its disordered structure. Finally, the property-performance correlations found in this work allow one to predict the carbon behavior in aqueous ECs. From an application point of view, the results emphasize that the optimal carbon for electrochemical capacitor application must combine a relatively high surface area $\left(>1000 \mathrm{~m}^{2} \mathrm{~g}^{-1}\right)$ in order to achieve high capacitance, an optimal micropore size that matches the ions in the electrolyte to ensure capacitance retention, a fraction of mesopores for efficient charge transport at high regimes and graphitic domains to maintain stability during cycling.

\section{ASSOCIATED CONTENT}

\section{(s) Supporting Information}

The Supporting Information is available free of charge at https://pubs.acs.org/doi/10.1021/acsami.0c18627.

Conductivity and $\mathrm{pH}$ of studied hydroxide solutions, Raman spectroscopy mapping data, textural properties of the electrode materials, correlation of carbon texture properties with electrochemical performance, textural and structural characterization of the KCl-NT material, Nyquist spectra at 0 and $0.8 \mathrm{~V}$ for the $\mathrm{MeCl}-\mathrm{T}$ material with matched $1 \mathrm{~mol} \mathrm{~L}-1 \mathrm{MeOH}$ electrolyte $\left(\mathrm{Me}=\mathrm{Li}^{+}\right.$,
$\mathrm{Na}^{+}, \mathrm{K}^{+}, \mathrm{Rb}^{+}, \mathrm{Cs}^{+}$), and cycling stability of $\mathrm{NaCl}-\mathrm{T}$ and CsCl-T electrodes in $1 \mathrm{~mol} \mathrm{~L}^{-1} \mathrm{NaOH}$ and $\mathrm{CsOH}$ (PDF)

\section{AUTHOR INFORMATION}

\section{Corresponding Authors}

Camélia Matei Ghimbeu - Institut de Science des Matériaux de Mulhouse (IS2M), Université de Haute-Alsace, CNRS UMR 7361, F-68100 Mulhouse, France; Université de Strasbourg, F67081 Strasbourg, France; Réseau sur le Stockage

Electrochimique de l'Energie (RS2E), CNRS FR3459, 80039

Amiens Cedex, France; O orcid.org/0000-0003-3600-5877; Email: camelia.ghimbeu@uha.fr

Krzysztof Fic - Institute of Chemistry and Technical Electrochemistry, Poznan University of Technology, 60-965

Poznan, Poland; Email: krzysztof.fic@put.poznan.pl

\section{Authors}

Anetta Platek-Mielczarek - Institute of Chemistry and Technical Electrochemistry, Poznan University of Technology, 60-965 Poznan, Poland

Cristina Nita - Institut de Science des Matériaux de Mulhouse (IS2M), Université de Haute-Alsace, CNRS UMR 7361, F68100 Mulhouse, France; Université de Strasbourg, F-67081 Strasbourg, France; Center for Advanced Laser Technologies (CETAL), National Institute for Lasers, Plasma and Radiation Physics, RO-77125 Magurele, Romania

Elzbieta Frackowiak - Institute of Chemistry and Technical Electrochemistry, Poznan University of Technology, 60-965 Poznan, Poland

Complete contact information is available at: https://pubs.acs.org/10.1021/acsami.0c18627

\section{Notes}

The authors declare no competing financial interest.

\section{ACKNOWLEDGMENTS}

Authors acknowledge the PHC POLONIUM PROJECT $\mathrm{N}^{\circ}$ $37783 \mathrm{YJ}$ and the European Commission as of the European Research Council for financial support by the Starting Grant project (GA 759603), under the European Union's Horizon 2020 Research and Innovation Programme. A.P.M. obtained financial support in the form of doctoral scholarship from the National Science Center (2019/32/T/ST4/00276) and programme im. Iwanowskiej from the Polish National Agency for Academic Exchange (NAWA). The authors thank Dr. Loïc Vidal and Dr. Jean-Marc Le Meins for the help with providing the TEM and XRD analyses.

\section{REFERENCES}

(1) Jun, J. H.; Song, H.; Kim, C.; Choi, I.-S.; Jeong, Y.; Lee, J.-H. Carbon-nanosheet based large-area electrochemical capacitor that is flexible, foldable, twistable, and stretchable. Small 2018, 14, 1702145.

(2) Fic, K.; Platek, A.; Piwek, J.; Frackowiak, E. Sustainable materials for electrochemical capacitors. Mater. Today 2018, 21, 437-454.

(3) Laheäär, A.; Przygocki, P.; Abbas, Q.; Béguin, F. Appropriate methods for evaluating the efficiency and capacitive behavior of different types of supercapacitors. Electrochem. Commun. 2015, 60, 2125.

(4) Gorska, B.; Bujewska, P.; Fic, K. Thiocyanates as attractive redoxactive electrolytes for high-energy and environmentally-friendly electrochemical capacitors. Phys. Chem. Chem. Phys. 2017, 19, 79237935. 
(5) Piwek, J.; Platek, A.; Fic, K.; Frackowiak, E. Carbon-based electrochemical capacitors with acetate aqueous electrolytes. Electrochim. Acta 2016, 215, 179-186.

(6) Slesinski, A.; Matei-Ghimbeu, C.; Fic, K.; Béguin, F.; Frackowiak, E. Self-buffered $\mathrm{pH}$ at carbon surfaces in aqueous supercapacitors. Carbon 2018, 129, 758-765.

(7) Wei, L.; Yushin, G. Nanostructured activated carbons from natural precursors for electrical double layer capacitors. Nano Energy 2012, 1, $552-565$.

(8) Guardia, L.; Suárez, L.; Querejeta, N.; Pevida, C.; Centeno, T. A. Winery wastes as precursors of sustainable porous carbons for environmental applications. J. Cleaner Prod. 2018, 193, 614-624.

(9) Lobato, B.; Suárez, L.; Guardia, L.; Centeno, T. A. Capacitance and surface of carbons in supercapacitors. Carbon 2017, 122, 434-445.

(10) Yan, J.; Miao, L.; Duan, H.; Zhu, D.; Lv, Y.; Xiong, W.; Li, L.; Gan, L.; Liu, M. Core-shell hierarchical porous carbon spheres with N/ O doping for efficient energy storage. Electrochim. Acta 2020, 358, 136899.

(11) Wang, J.; Kaskel, S. KOH activation of carbon-based materials for energy storage. J. Mater. Chem. 2012, 22, 23710-23725.

(12) Dastgheib, S. A.; Rockstraw, D. A. Pecan shell activated carbon: synthesis, characterization, and application for the removal of copper from aqueous solution. Carbon 2001, 39, 1849-1855.

(13) Maciá-Agulló, J. A.; Moore, B. C.; Cazorla-Amorós, D.; LinaresSolano, A. Activation of coal tar pitch carbon fibres: Physical activation vs. chemical activation. Carbon 2004, 42, 1367-1370.

(14) Frackowiak, E. Carbon materials for supercapacitor application. Phys. Chem. Chem. Phys. 2007, 9, 1774-1785.

(15) Gu, W.; Yushin, G. Review of nanostructured carbon materials for electrochemical capacitor applications: advantages and limitations of activated carbon, carbide-derived carbon, zeolite-templated carbon, carbon aerogels, carbon nanotubes, onion-like carbon, and graphene. Wires Energy Environ 2014, 3, 424-473.

(16) Meng, Y.; Gu, D.; Zhang, F.; Shi, Y.; Yang, H.; Li, Z.; Yu, C.; Tu, B.; Zhao, D. Ordered mesoporous polymers and homologous carbon frameworks: amphiphilic surfactant templating and direct transformation. Angew. Chem., Int. Ed. 2005, 44, 7053-7059.

(17) Ma, T.-Y.; Liu, L.; Yuan, Z.-Y. Direct synthesis of ordered mesoporous carbons. Chem. Soc. Rev. 2013, 42, 3977-4003.

(18) Libbrecht, W.; Verberckmoes, A.; Thybaut, J. W.; Van Der Voort, P.; De Clercq, J. Soft templated mesoporous carbons: Tuning the porosity for the adsorption of large organic pollutants. Carbon 2017, $116,528-546$.

(19) Saha, D.; Zacharia, R.; Naskar, A. K. Soft-templated mesoporous carbons: chemistry and structural characteristics. ACS Symp. Ser. 2014, $61-83$.

(20) Schnucklake, M.; Kuecken, S.; Fetyan, A.; Schmidt, J.; Thomas, A.; Roth, C. Salt-templated porous carbon-carbon composite electrodes for application in vanadium redox flow batteries. J. Mater. Chem. A 2017, 5, 25193-25199.

(21) Masika, E.; Mokaya, R. High surface area metal salt templated carbon aerogels via a simple subcritical drying route: preparation and $\mathrm{CO}_{2}$ uptake properties. RSC $A d v$. 2013, 3, 17677-17681.

(22) Vilian, A. T. E.; Song, J. Y.; Lee, Y. S.; Hwang, S.-K.; Kim, H. J.; Jun, Y.-S.; Huh, Y. S.; Han, Y.-K. Salt-templated three-dimensional porous carbon for electrochemical determination of gallic acid. Biosens. Bioelectron. 2018, 117, 597-604.

(23) Nita, C.; Bensafia, M.; Vaulot, C.; Delmotte, L.; Matei Ghimbeu, $\mathrm{C}$. Insights on the synthesis mechanism of green phenolic resin derived porous carbons via a salt-soft templating approach. Carbon 2016, 109, 227-238.

(24) Platek, A.; Nita, C.; Ghimbeu, C. M.; Frąckowiak, E.; Fic, K. Electrochemical capacitors operating in aqueous electrolyte with volumetric characteristics improved by sustainable templating of electrode materials. Electrochim. Acta 2020, 338, 135788.

(25) Miao, L.; Duan, H.; Wang, Z.; Lv, Y.; Xiong, W.; Zhu, D.; Gan, L.; Li, L.; Liu, M. Improving the pore-ion size compatibility between poly(ionic liquid)-derived carbons and high-voltage electrolytes for high energy-power supercapacitors. Chem. Eng. J. 2020, 382, 122945.
(26) Sánchez-Sánchez, Á.; Centeno, T. A.; Suárez-García, F.; Martínez-Alonso, A.; Tascón, J. M. D. The importance of electrode characterization to assess the supercapacitor performance of ordered mesoporous carbons. Microporous Mesoporous Mater. 2016, 235, 1-8.

(27) Gamby, J.; Taberna, P. L.; Simon, P.; Fauvarque, J. F.; Chesneau, M. Studies and characterisations of various activated carbons used for carbon/carbon supercapacitors. J. Power Sources 2001, 101, 109-116.

(28) Vix-Guterl, C.; Frackowiak, E.; Jurewicz, K.; Friebe, M.; Parmentier, J.; Béguin, F. Electrochemical energy storage in ordered porous carbon materials. Carbon 2005, 43, 1293-1302.

(29) Raymundo-Piñero, E.; Kierzek, K.; Machnikowski, J.; Béguin, F. Relationship between the nanoporous texture of activated carbons and their capacitance properties in different electrolytes. Carbon 2006, 44, 2498-2507.

(30) Feng, H.; Wei, Y.; Shao, C.; Lai, Y.; Feng, S.; Dong, Z. Study on overpotential of the electrochemical hydrogen storage of multiwall carbon nanotubes. Int. J. Hydrogen Energy 2007, 32, 1294-1298.

(31) Xing, W.; Qiao, S. Z.; Ding, R. G.; Li, F.; Lu, G. Q.; Yan, Z. F.; Cheng, H. M. Superior electric double layer capacitors using ordered mesoporous carbons. Carbon 2006, 44, 216-224.

(32) Centeno, T. A.; Stoeckli, F. The assessment of surface areas in porous carbons by two model-independent techniques, the DR equation and DFT. Carbon 2010, 48, 2478-2486.

(33) Centeno, T. A.; Sereda, O.; Stoeckli, F. Capacitance in carbon pores of 0.7 to $15 \mathrm{~nm}$ : a regular pattern. Phys. Chem. Chem. Phys. 2011, $13,12403-12406$.

(34) Ania, C. O.; Armstrong, P. A.; Bandosz, T. J.; Beguin, F.; Carvalho, A. P.; Celzard, A.; Frackowiak, E.; Gilarranz, M. A.; László, K.; Matos, J.; Pereira, M. F. R. Engaging nanoporous carbons in "beyond adsorption" applications: characterization, challenges and performance. Carbon 2020, 164, 69-84.

(35) Chmiola, J.; Yushin, G.; Gogotsi, Y.; Portet, C.; Simon, P.; Taberna, P. L. Anomalous increase in carbon capacitance at pore sizes less than 1 nanometer. Science 2006, 313, 1760-1763.

(36) Largeot, C.; Portet, C.; Chmiola, J.; Taberna, P.-L.; Gogotsi, Y.; Simon, P. Relation between the ion size and pore size for an electric double-layer capacitor. J. Am. Chem. Soc. 2008, 130, 2730-2731.

(37) Merlet, C.; Rotenberg, B.; Madden, P. A.; Taberna, P.-L.; Simon, P.; Gogotsi, Y.; Salanne, M. On the molecular origin of supercapacitance in nanoporous carbon electrodes. Nat. Mater. 2012, 11, 306-310.

(38) Kim, T.; Jung, G.; Yoo, S.; Suh, K. S.; Ruoff, R. S. Activated Graphene-Based Carbons as Supercapacitor Electrodes with Macroand Mesopores. ACS Nano 2013, 7, 6899-6905.

(39) Redondo, E.; Ségalini, J.; Carretero-González, J.; Goikolea, E.; Mysyk, R. Relation between texture and high-rate capacitance of oppositely charged microporous carbons from biomass waste in acetonitrile-based supercapacitors. Electrochim. Acta 2019, 293, 496503.

(40) Xue, B.; Jin, L.; Chen, Z.; Zhu, Y.; Wang, Z.; Liu, X.; Wang, X. The template effect of silica in rice husk for efficient synthesis of the activated carbon based electrode material. J. Alloys Compd. 2019, 789, $777-784$

(41) Xu, F.; Qiu, Y.; Han, H.; Jiang, G.; Zhao, R.; Zhang, E.; Li, H.; Wang, H.; Kaskel, S. Manipulation of carbon framework from the microporous to nonporous via a mechanical-assisted treatment for structure-oriented energy storage. Carbon 2020, 159, 140-148.

(42) Qie, L.; Chen, W.; Xu, H.; Xiong, X.; Jiang, Y.; Zou, F.; Hu, X.; Xin, Y.; Zhang, Z.; Huang, Y. Synthesis of functionalized 3D hierarchical porous carbon for high-performance supercapacitors. Energy Environ. Sci. 2013, 6, 2497-2504.

(43) Kibona, T. E.; Shao, G. N.; Kim, H. T.; King'ondu, C. K. Specific capacitance-pore texture relationship of biogas slurry mesoporous carbon $/ \mathrm{MnO}_{2}$ composite electrodes for supercapacitors. Nano-Struct. Nano-Objects 2019, 17, 21-33.

(44) Zheng, Y.; Deng, T.; Zhang, W.; Zheng, W. Optimizing the micropore-to-mesopore ratio of carbon-fiber-cloth creates record-high specific capacitance. J. Energy Chem. 2020, 47, 210-216. 
(45) Yang, X.; Liu, X.; Cao, M.; Deng, Y.; Li, X. Tailoring porous carbon aerogels from bamboo cellulose fibers for high-performance supercapacitors. J. Porous Mater. 2019, 26, 1851-1860.

(46) Nita, C.; Fullenwarth, J.; Monconduit, L.; Le Meins, J. M.; Fioux, P.; Parmentier, J.; Matei Ghimbeu, C. Eco-friendly synthesis of $\mathrm{SiO}_{2}$ nanoparticles confined in hard carbon: A promising material with unexpected mechanism for Li-ion batteries. Carbon 2019, 143, 598609.

(47) Shannon, R. D.; Prewitt, C. T. Effective Ionic Radii in Oxides and Fluorides. Acta Crystallogr., Sect. B 1969, 25, 925-946.

(48) Persson, I. Hydrated metal ions in aqueous solution: How regular are their structures? Pure Appl. Chem. 2010, 82, 1901-1917.

(49) Buiel, E. R.; George, A. E.; Dahn, J. R. Model of micropore closure in hard carbon prepared from sucrose. Carbon 1999, 37, 13991407.

(50) Béguin, F.; Presser, V.; Balducci, A.; Frackowiak, E. Carbons and electrolytes for advanced supercapacitors. Adv. Mater. 2014, 26, 22192251.

(51) Prehal, C.; Koczwara, C.; Jäckel, N.; Schreiber, A.; Burian, M.; Amenitsch, H.; Hartmann, M. A.; Presser, V.; Paris, O. Quantification of ion confinement and desolvation in nanoporous carbon supercapacitors with modelling and in situ X-ray scattering. Nat. Energy 2017, 2, 16215 .

(52) Merlet, C.; Péan, C.; Rotenberg, B.; Madden, P. A.; Daffos, B.; Taberna, P.-L.; Simon, P.; Salanne, M. Highly confined ions store charge more efficiently in supercapacitors. Nat. Commun. 2013, 4, 2701.

(53) Pean, C.; Daffos, B.; Rotenberg, B.; Levitz, P.; Haefele, M.; Taberna, P.-L.; Simon, P.; Salanne, M. Confinement, desolvation, and electrosorption effects on the diffusion of ions in nanoporous carbon electrodes. J. Am. Chem. Soc. 2015, 137, 12627-12632.

(54) Griffin, J. M.; Forse, A. C.; Wang, H.; Trease, N. M.; Taberna, P.L.; Simon, P.; Grey, C. P. Ion counting in supercapacitor electrodes using NMR spectroscopy. Faraday Discuss. 2014, 176, 49-68.

(55) Urita, K.; Ide, N.; Isobe, K.; Furukawa, H.; Moriguchi, I. Enhanced electric double-layer capacitance by desolvation of lithium ions in confined nanospaces of microporous carbon. ACS Nano 2014, 8 , 3614-3619.

(56) Mysyk, R.; Raymundo-Pinero, E.; Beguin, F. Saturation of subnanometer pores in an electric double-layer capacitor. Electrochem. Commun. 2009, 11, 554-556.

(57) Taberna, P. L.; Simon, P.; Fauvarque, J. F. Electrochemical Characteristics and Impedance Spectroscopy Studies of CarbonCarbon Supercapacitors. J. Electrochem. Soc. 2003, 150, A292.

(58) Niu, C.; Sichel, E. K.; Hoch, R.; Moy, D.; Tennent, H. High power electrochemical capacitors based on carbon nanotube electrodes. Appl. Phys. Lett. 1997, 70, 1480-1482.

(59) Raymundo-Piñero, E.; Cadek, M.; Béguin, F. Tuning carbon materials for supercapacitors by direct pyrolysis of seaweeds. Adv. Funct. Mater. 2009, 19, 1032-1039.

(60) Lozano-Castelló, D.; Cazorla-Amorós, D.; Linares-Solano, A.; Shiraishi, S.; Kurihara, H.; Oya, A. Influence of pore structure and surface chemistry on electric double layer capacitance in non-aqueous electrolyte. Carbon 2003, 41, 1765-1775.

(61) Gryglewicz, G.; Machnikowski, J.; Lorenc-Grabowska, E.; Lota, G.; Frackowiak, E. Effect of pore size distribution of coal-based activated carbons on double layer capacitance. Electrochim. Acta 2005, 50, 1197-1206.

(62) Lee, J.; Kim, J.; Hyeon, T. Recent progress in the synthesis of porous carbon materials. Adv. Mater. 2006, 18, 2073-2094.

(63) Fic, K.; Płatek, A.; Piwek, J.; Menzel, J.; Ślesiński, A.; Bujewska, P.; Galek, P.; Frąckowiak, E. Revisited insights into charge storage mechanisms in electrochemical capacitors with $\mathrm{Li}_{2} \mathrm{SO}_{4}$-based electrolyte. Energy Storage Mater. 2019, 22, 1-14.

(64) Hatzell, K. B.; Beidaghi, M.; Campos, J. W.; Dennison, C. R.; Kumbur, E. C.; Gogotsi, Y. A high performance pseudocapacitive suspension electrode for the electrochemical flow capacitor. Electrochim. Acta 2013, 111, 888-897.

(65) Gao, Y.; Presser, V.; Zhang, L.; Niu, J. J.; McDonough, J. K.; Pérez, C. R.; Lin, H.; Fong, H.; Gogotsi, Y. High power supercapacitor electrodes based on flexible TiC-CDC nano-felts. J. Power Sources 2012, 201, 368-375.

(66) Jäckel, N.; Weingarth, D.; Zeiger, M.; Aslan, M.; Grobelsek, I.; Presser, V. Comparison of carbon onions and carbon blacks as conductive additives for carbon supercapacitors in organic electrolytes. J. Power Sources 2014, 272, 1122-1133.

(67) McDonough, J. K.; Frolov, A. I.; Presser, V.; Niu, J.; Miller, C. H.; Ubieto, T.; Fedorov, M. V.; Gogotsi, Y. Influence of the structure of carbon onions on their electrochemical performance in supercapacitor electrodes. Carbon 2012, 50, 3298-3309.

(68) Ma, C.; Li, Y.; Shi, J.; Song, Y.; Liu, L. High-performance supercapacitor electrodes based on porous flexible carbon nanofiber paper treated by surface chemical etching. Chem. Eng. J. 2014, 249, $216-225$. 